\title{
1 Earliest evidence for frugivory and seed dispersal by birds
}

2

$3 \mathrm{Han} \mathrm{Hu}^{1,2 *}$, Yan Wang ${ }^{3}$, Paul G. McDonald ${ }^{2}$, Stephen $\mathrm{Wroe}^{2}$, Jingmai K. O'Connor ${ }^{4,5,6}$,

4 Alexander Bjarnason ${ }^{1}$, Joseph J. Bevitt ${ }^{7}$, Xuwei Yin ${ }^{8}$, Xiaoting Zheng ${ }^{3,8}$, Zhonghe Zhou ${ }^{5,6}$,

$5 \quad$ Roger B.J. Benson ${ }^{1}$

6

71 Department of Earth Sciences, University of Oxford, Oxford, OX1 3AN, UK;

82 Zoology Division, School of Environmental and Rural Sciences, University of New

9 England, Armidale, NSW 2351, Australia;

103 Institute of Geology and Paleontology, Linyi University, Linyi, Shandong, 276000, China;

114 Field Museum of Natural History, Chicago, Illinois 60605, USA;

125 Key Laboratory of Vertebrate Evolution and Human Origins, Institute of Vertebrate

13 Paleontology and Paleoanthropology, Chinese Academy of Sciences, 10010 Beijing, China;

146 Chinese Academy of Sciences Center for Excellence in Life and Paleoenvironment, 10010

15 Beijing, China;

167 Australian Centre for Neutron Scattering, Australian Nuclear Science and Technology

17 Organisation, Sydney, Australia;

188 Shandong Tianyu Museum of Nature, China

19

$20 *$ For correspondence: wangyan6696@lyu.edu.cn (Y.W.); han.hu@earth.ox.ac.uk (H.H.) 


\section{Abstract}

22 The Early Cretaceous diversification of birds was a major event in the history of terrestrial ecosystems, occurring during the earliest phase of the Cretaceous Terrestrial Revolution. Frugivorous birds play an important role in seed dispersal today, and may have done so since their origins. However, evidence of this has been lacking. Jeholornis is one of the earliestdiverging birds, only slightly more derived than Archaeopteryx, but its cranial anatomy has been poorly understood, obscuring diet-related functional interpretations. Originally hypothesised to be granivorous based on seeds preserved as gut contents, this interpretation has become controversial. We conducted high-resolution synchrotron tomography on an exquisitely preserved new skull of Jeholornis, revealing remarkable cranial plesiomorphies combined with a specialised rostrum. We use this to provide a near-complete cranial reconstruction of Jeholornis, and exclude the possibility that Jeholornis was granivorous, based on morphometric analyses of the mandible (3D) and cranium (2D), and comparisons with the 3D alimentary contents of extant birds. We show that Jeholornis was at least seasonally frugivorous, providing the earliest evidence for fruit consumption in birds, and indicating that seed dispersal was present from early in the avian radiation. As highly-mobile seed dispersers, early frugivorous birds could expand the scope for biotic dispersal in plants, and may explain, in part, the subsequent evolutionary expansion of fruits, indicating a potential role of bird-plant interactions in the Cretaceous Terrestrial Revolution.

\section{Introduction}

Birds are among the most speciose extant vertebrate groups, playing unique ecological roles through their diverse flight and dietary adaptations (Prum et al., 2015). Modern birds

44 include both specialised and opportunistic frugivores, that collectively are major consumers of fruits and important agents of seed dispersal. The early ecological diversification of birds 
in the Early Cretaceous (>130 Ma) (Yang et al., 2020) was a landmark event in the evolution

47 of terrestrial ecosystems, adding considerably to species richness of terrestrial ecosystems (Benson, 2018; Yu et al., 2021), and with impacts on the evolutionary histories of other flying groups (Benson et al., 2014b; Clapham and Karr, 2012). The origin and early diversification of birds in the Early Cretaceous was followed by a considerable long-term expansion of the abundance and disparity of fruits and fruit-like structures (Eriksson et al., 2000a; Eriksson, 2008), as part of the major floral transition from gymnosperm- to angiosperm-dominated floras that is RIWHQUHIHUUHGWRDVWKH $2 \&$ UHWDFHRXV7HUUHVWULD 5HY ROX W LRQ¥7ßBenton, 2010; Lloyd et al., 2008). A macroevolutionary connection between early birds and this important event of fruit evolution has been suggested (Pejchar et al., 2008; Sekercioglu, 2006; Tiffney, 2004), but is so far unsubstantiated by fossil evidence of frugivory, presenting an obstacle to our understanding of the evolutionary origins of an important aspect of plant-animal interactions.

The Jeholornithiformes from the Early Cretaceous Jehol Biota of China are one of the earliest-diverging avian lineages, retaining a plesiomorphically elongate, bony tail, which is absent in all other birds exception for the Late Jurassic Archaeopteryx (Wang et al., 2018; Zhou and Zhang, 2002). They also possess several advanced, flight-related morphologies, suggesting a unique form of powered flight $2 \partial \& R Q Q R U H W D O=K H Q J H W D O=K R X$ and Zhang, 2002). The most representative jeholornithiform, Jeholornis, has been interpreted as the earliest granivorous bird, based on the reportedly $\geq$ deep $¥$ mandible and traces identified as seeds preserved in the abdominal area (Zhou and Zhang, 2002). Reduced dentition and the presence of a gastric mill further suggest a herbivorous diet $2 \partial \& R Q Q R U H W D O$. However, there is no consensus on whether seeds entered the gut of Jeholornis, and other early birds, through deliberate seed consumption (granivory), or through consumption of fleshy 


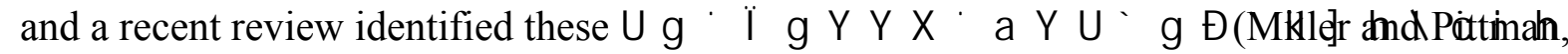
2021). Clarifying between these two hypotheses has significant implications with regards to the early evolution of bird-plant interactions, because frugivory results from beneficial coevolutionary mutualism, whereas granivory does not. This therefore is relevant to understanding whether early birds could have been important agents of seed dispersal with a potential co-evolutionary influence on plant evolution during the KTR.

Interpretations regarding diet in Jeholornis and other potentially-granivorous early birds (Ksepka et al., 2019; Zheng et al., 2018, 2011) have previously been framed using qualitative observations and subjective assessments, with minimal formal comparison to extant species, and in the absence of a detailed understanding of jeholornithiform cranial anatomy (Lefèvre

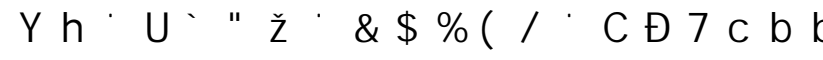
. We here report an exquisitely preserved new Jeholornis specimen, STM 3-8, from the Shandong Tianyu Museum of Nature, Pingyi, China. We use high quality three-dimensional (3D) data acquired through the synchrotron tomography to reveal the key cranial features of this taxon and build the most accurate cranial reconstruction of a stem bird to date. This information is used to test and determine the two diet hypotheses of Jeholornis, through geometric morphometric (GMM) analyses of the mandible (3D) and cranium (2D), and high-resolution computed tomography (CT) 3D visualisations of the alimentary contents of extant birds. Our approach demonstrates the importance of applying multiple methods simultaneously to solve complex palaeoecological questions.

\section{Results}

\section{Cranial Anatomy}


Due to its key phylogenetic position, Jeholornis has been frequently studied and cited, and many specimens are known. However, because specimens are often compressed, and are preserved in slabs, little unequivocal cranial information has been available (Lefèvre et al.,

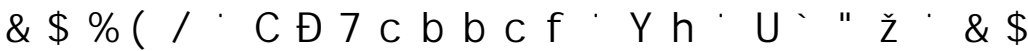

Zhang, 2003, 2002). Our three-dimensional (3D) reconstruction of the exquisitely preserved skull of Jeholornis STM 3-8 (Figure 1; for detailed taxonomic information see

Supplementary Information) reveals that Jeholornis retains a plesiomorphic diapsid skull, and provides considerable new anatomical data.

Although an unfused postorbital was previously inferred based on the basal phylogenetic position of Jeholornis (Wang and Hu, 2017), STM 3-8 provides the first direct evidence of this. The postorbital is proportionally large with a well-developed jugal process that contacts the jugal, forming a robust, complete postorbital bar (Figure 1). This is a plesiomorphy shared with non-avian theropods and other stem birds including Archaeopteryx and Sapeornis (Hu et al., 2020a; Rauhut et al., 2018), contrasting with the reduced or absent postorbital bar in the Ornithothoraces including modern birds (Hu et al., 2020b). The squamosal possesses a postorbital process that likely contacted the postorbital to form the supratemporal arch. The ventral process of the squamosal is short and would not have contacted the quadratojugal. The squamosal of Jeholornis is remarkably anteroposteriorly broad even compared to that of Archaeopteryx (Rauhut, 2014; Rauhut et al., 2018). A complete bony upper temporal bar is supposed to exist based on the articular facet in the postorbital, while this bar is broken and probably linked by ligament in Late Cretaceous bird Ichthyornis (Field et al., 2018). The palatal complex is nearly completely preserved, including the palatine, pterygoid and vomer; the absence of the ectopterygoid is most likely preservational (Figure 1). The palate of Jeholornis exhibits few modifications from the non-avian theropod condition, and closely resembles that of Archaeopteryx (Elzanowski and Wellnhofer, 1996; Mayr et al., 
2007; Rauhut et al., 2018). The palatine is broad with a well-developed jugal process that contacts the maxilla. The pterygoid is elongated with no sign of the shortening that occurs in more derived birds and the pterygoid flange is well-developed, indicating the presence of an ectopterygoid. The vomer is dorsoventrally thin with bifurcated caudal flanges oriented nearly vertical to the rostral body, similar to the condition in Sapeornis (Hu et al., 2019). While the temporal and palatal regions retain plesiomorphies, the rostrum of Jeholornis is heavily modified. The new specimen reveals that its premaxillae corpora are fused while the frontal processes remain separate. Rostral fusion of the premaxillae is also present in extant birds, confuciusornithiforms and several enantiornithines e.g., Linyiornis and Shangyang (Wang and Zhou, 2019; Wang et al., 2016). Its occurrence in Jeholornis indicates that it occurred phylogenetically earlier than previously thought. Jeholornis also shows dental reduction, with an edentulous premaxilla, two rostrally restricted maxillary teeth and three extremely tiny teeth in the dentary $2 \partial \& R Q Q R U H W D O=K R X D Q G=K D Q J \quad$ (Figure 1).

\section{Geometric Morphometric Analyses}

We digitally reassembled the cranium and mandible of Jeholornis STM 3-8, producing 2D cranial and 3D mandible reconstructions (Figure 1). These were included in a 3D GMM analysis of the mandible and a 2D analysis of the cranium of extant birds and select extinct pennaraptorans (for landmark definitions see Figure 2 - figure supplements 1 and Figure 2 Source data $1 \& 2)$, to evaluate the similarity of the mandible and cranium of Jeholornis to extant birds with different diets. Diets of extant birds were separated into five categories: (1) Seed-crackers (parrots): granivores that de-husk and fragment seeds using the beak prior to ingestion; (2) Seed-crackers (passerines): granivores that de-husk but do not extensively fragment seeds using the beak prior to ingestion; (3) Seed-grinders: granivores that primarily 
144 process seeds using a gastric mill, with minimal beak processing; (4) Fruit eaters; and (5)

145 Other diets (such as folivores, carnivores and omnivores).

146 Mandibular Morphospace. The principal components analysis (PCA) results reveal

147 that a large portion of mandibular shape variation $(\mathrm{PC} 1: 36 \%)$ is related to the relative length

148 of the mandible compared to its rostral depth: positive values of PC1 indicate short, deep

149 mandibles, whereas negative values indicate long, low mandibles. PC2 explains $34 \%$ of

150 variation and is also related to the relative depth of the mandible, with positive values

151 indicating low mandibles with coronoid eminence absent or less developed, and negative

152 values indicating deep mandibles with a large coronoid eminence. PC3 (10\% of variation) is

153 related to the curvature, with positive values indicating a straight profile in lateral view, and

154 negative values indicating rostroventral curvature of the rostral portion of the mandible

155 (Figure 2A, B).

156 The results plot Jeholornis near the centre of mandibular morphospace. Seed-crackers,

157 especially parrots, are clearly separated from the other diet types including Jeholornis in

158 mandibular morphospace. They occupy a distinct region with high, positive values of PC1

159 and low, negative values of PC2, reflecting their deep and anteroposteriorly short mandibles

160 with a large coronoid process and deep mandibular symphysis, which suits their seed-

161 cracking diet by reducing the beak failure risk during cracking (Soons et al., 2015, 2010). The

162 frugivorous parrot \pm Psittrichas fulgidus (Billerman et al., 2020) \pm has a shallow mandible

163 compared to those seed-cracking parrots, and plots closer to the distribution of non-parrots,

164 consistent with the hypothesis that species can secondarily lose specialisations associated

165 with their ancestral diet.

166 Seed cracking passerines also occupy an area with negative PC2 values compared to

167 most frugivores and seed-grinders, being closer to seed-cracking parrots. They also show

168 negative values of PC3, indicating that they have more downward inclined mandibles, which 
is related to their ability to de-husk seeds (Meij and Bout, 2008). Therefore, finches are also

170

171

172

173

174

175

176

177

178

179

180

181

182

183

184

185

186

187

188

189

190

191

192

193

clearly distinct from the position of Jeholornis in mandibular morphospace (Figure 2A, B), rejecting the previous hypothesis of Jeholornis as a seed cracker (both parrot-type and finchtype) (Zhou and Zhang, 2002).

Jeholornis is plotted within the overlapping range of frugivores, seed-grinders, and birds ZLW KAWKHUG FHghr\&aA, B; Figure 2 - figure supplements 2A, B). Frugivores and seedgrinders show wide and highly overlapping distributions (Figure 2A, B), indicating that

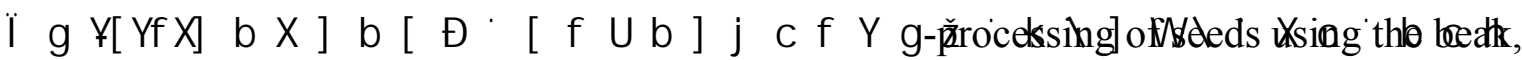
H[K LELWOLWW OHVSHFLDOLVDW LRQRIPDQGLEXODUPRU \&KFROAFINERASDUHGWR NHH granivores. Therefore, although our results exclude Jeholornis from being a seed cracker, they cannot distinguish between the hypotheses that seeds entered the gut of Jeholornis due to frugivory, or due to seed-grinding granivory.

Cranial Morphospace. Cranial shape distinguishes between our focal diet categories less effectively than mandibular shape (Figure 2C, D, Figure 2 - figure supplements 2C, D). Nevertheless, some separation is still evident, especially between seed-crackers and other dietary groups. This also indicates that Jeholornis was not a seed-cracking granivore. Extant seed-crackers occupy positive values of both PC1 and PC2, compared to more centrallypositioned frugivores and seed-grinders. Variation in PC1 (45\%) is related to the relative length of the rostrum compared to the jugal bar, with positive values indicating a shorter rostrum. Variation in PC2 (14\%) is related to the depth and curvature of the rostrum, with positive values indicating deeper and rostroventrally curved rostra, present in seed-crackers and toucans (Ramphastos, which differs from seed-crackers in having a negative PC1 score). Variation in PC3 is related to the relative size of the orbit and naris, with positive values indicating smaller orbits and naris. Because some fossil samples included in our analyses are incomplete, we did not include the skull roof in this analysis. Our results indicate that seed- 
crackers have relatively short, deep and rostroventrally curved rostra compared to most other birds, including Jeholornis, Sapeornis and other Mesozoic taxa.

Mesozoic taxa are mostly separated from modern birds along PC2 and PC3, occupying negative values of PC2 and positive values of PC3 separately (Figure 2C, D). Among them, Jeholornis and Sapeornis are more similar to extant birds along PC2, which describes rostral morphology. This may reflect the dietary specialization of Jeholornis and Sapeornis (frugivory-like or granivory) compared to other Mesozoic taxa. Nevertheless, they cluster with other Mesozoic taxa along cranial PC3, indicating conservative aspects shared with nonavian theropods, especially a proportionally small orbit and external naris.

Alimentary Content Analyses

Our morphometric analyses indicate that Jeholornis ZDV QRW DN HFUGD F N HU DEX W GR QRW

distinguish between frugivorous and seed-grinding granivorous diets. We therefore conducted a comparison of the alimentary contents of Jeholornis (Figure 3) with selected modern birds (Figure 4) using high resolution CT scanning. Our modern bird sample includes frugivores (Manucodia comrii, Curl-crested manucode; Bombycilla garrulus, Bohemian waxwing), seed-cracking parrots (Conuropsis carolinensis, Carolina parakeet), seed-cracking passerines (Geospiza fuliginosa, Small ground-finch; Calcarius lapponicus, Lapland longspur), and seed-grinding granivores (Ectopistes migratorius, Passenger pigeon; Pedionomus torquatus,

213 Plains-wanderer; Thinocorus rumicivorus, Least seedsnipe) (detailed specimen information see Figure 4 - Source data 1; detailed descriptions of their alimentary contents see Methods and Materials). strongly indicated by fragmentation (in seed-crackers) or abrasion (in seed-grinders) of seeds 218 in the alimentary canals, which is likely a prerequisite for nutrient extraction. The seed 
remains are highly fragmented in seed-cracking parrots (Figure 4E), whereas in seed-cracking passerines, although the crop contents are almost intact, those in the stomach are also highly fragmentary (Figure 4D, Figure 4 - figure supplements 1E, F). This is consistent with behavioural observations of finches and other granivorous passerines (Billerman et al., 2020), in which seed-cracking passerines use the beak only to remove the outer coats of seeds, and do not fragment the seed before ingestion, differing from parrots that can fragment seeds prior to ingestion (Figure 4E). Fragmentation (in granivorous passerines) is completed later by the gastric mill, showing a similar condition of seed-grinders. Fragmentation of seeds in passerines is primarily achieved through the gastric mill, similar to some seed-grinders e.g. Ectopistes migratorius (Passenger pigeon) (Figure 4C, Figure 4 - figure supplements 1B). However, in most seed-grinders the gut contents consist of abraded and partially-damaged, rather than highly-fragmented, seed remains (Figure 4B, Figure 4 - figure supplements 2A-F). typically co-occurred with gastroliths (Figure 4B-E). Gastroliths are especially abundant in some seed-grinders and seed-cracking passerines (Figure 4B, D) compared to the parrot

234 (Figure 4E) and pigeon (Figure 4C). In contrast, the seed remains in frugivores are

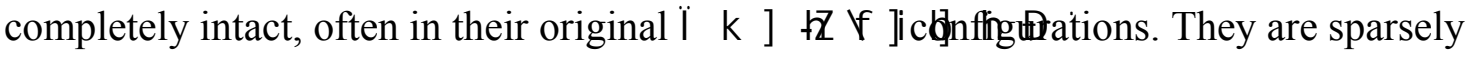
dispersed in the alimentary tract, sometimes accompanied by a few tiny gastroliths (Figure 4A, Figure 4 - figure supplements 1A, C, D). The seed remains preserved in currently known Jeholornis specimens most closely resemble the condition in frugivores, being completely intact and sparsely dispersed (Figure 3A-C) compared to the gastroliths preserved in other individuals (Figure 3D) $2 \partial \& R Q Q R U 2 \partial \& R Q Q R U H W D 02 \partial \& R Q Q R U D Q G=K R X$

\section{Discussion}



diverging bird Jeholornis reveals a plesiomorphic, diapsid skull, sharing numerous features

245

with non-avian theropods. These features include a complete postorbital bar, unreduced squamosal, and unmodified palate (Hu et al., 2020b, 2020a, 2019; Rauhut et al., 2018), reinforcing evidence for an early-diverging phylogenetic position among birds (Wang et al., 2018; Zhou and Zhang, 2002). Nevertheless, compared to Archaeopteryx (Rauhut, 2014;

Rauhut et al., 2018), Jeholornis also possesses clear diet-related specialisations of the rostrum including partial fusion of the premaxillae and a strongly reduced dentition.

Our GMM analyses reveal that the mandibular and cranial shapes of Jeholornis and Sapeornis are distinct from those of seed-cracking granivorous birds, consistent with earlier assumptions that the delicate, vestigial dentary teeth of Jeholornis would be too prone to

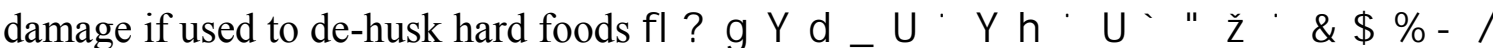
$20182 \partial \& R Q Q R U D Q G=K R X \quad$, and contrary to previous claims that the reportedly $\geq$ deep $¥$ mandible of Jeholornis is suitable for such a behaviour (Zhou and Zhang, 2002). Although their mandibular and cranial shapes occupy the morphospace in which several diets overlap, including frugivory and gastric seed-grinding granivory, these diets can be distinguished through comparing the condition of ingested remains in the alimentary tract in modern birds.

Known stomach contents preserved in Jeholornis take two forms in different fossil specimens, which include: (1) individuals with sparsely distributed and entirely intact seeds (Figure 3A-C) (Zhou and Zhang, 2002), and (2) those with a relatively small concentration of

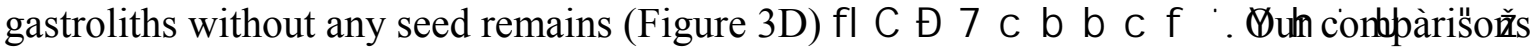
with modern birds indicate that the first group of Jeholornis individuals ingested fleshy propagules (frugivory), rather than consuming seeds for nutrient extraction (granivory). We cannot interpret the presence of gastroliths in the second group of individuals, because gastroliths are widespread in extant birds with a wide range of diets e.g. insectivory, 


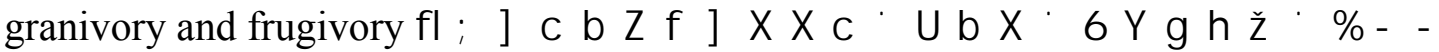

Wings, 2007), making it impossible to infer diet from this evidence alone. Crucially, no Jeholornis specimen preserves seeds and gastroliths together $2 \partial \& R Q Q R U 2 \partial \& R Q Q R U$ and Zhou, 2020) (and preserved seeds within Jeholornis are not abraded), which would be required as evidence for seed-grinding granivory.

Variation in alimentary contents among individuals of Jeholornis are best interpreted as evidence of seasonal variation in diet, or potentially other intraspecific variation in diet $2 \partial \& R Q Q R U 2 \partial \& R Q Q R U H W D O$ 18). It is possible that Jeholornis consumed fleshy propagules during the seasons in which such food sources were available, but fed on other food sources such as invertebrates or foliage using the gastric mill during other seasons. Similar seasonal dietary shifts are quite common in modern birds that feed on fruits as part of their diet such as Ruffed Grouse (Bonasa umbellus) and Hoatzin (Opisthocomus hoazin) (Billerman et al., 2020). If our inferences regarding Jeholornis are correct, this dietary flexibility can be traced back to the earliest stages of bird evolution.

The evidence for frugivory in Jeholornis demonstrates that early birds with seeds preserved in the abdominal area cannot be identified as granivores without further evidence from cranial morphology, or the co-occurrence of abraded or fragmented seeds with gastroliths. It was recently suggested that Sapeornis, Eogranivora and even some enantiornithines may also have been frugivorous (Ksepka et al., 2019; Mayr et al., 2020). However, the evidence for this remains equivocal. Sapeornis and Eogranivora preserve apparently whole seeds in the crop, but only gastroliths in the abdominal area (Zheng et al., 2018, 2011), consistent with both seed-grinding granivory and passerine-like seed-cracking (Figure 4C, D). Therefore, Jeholornis is so far the only Mesozoic bird that provides strong evidence of frugivory. However, this should not be taken as evidence that frugivory was rare. Direct evidence on diet in fossil birds is rare and preserved gut contents are limited to just a 
293 few individuals from a small number of Early Cretaceous fossil deposits in China and Europe OL OOHUDQG 3LWW PDQ22\&RQQRU . Given this low level of current knowledge,

295 evidence for at least seasonal frugivory in Jeholornis is important in demonstrating that at least some early birds ate fruits.

Flight-related anatomical specialisations suggest that Jeholornis was a competent flier in spite of its early-diverging phylogenetic position $2 \partial \& R Q Q R U H W D O=K H Q J H W D O$ Zhou and Zhang, 2002). Although flight is not an exclusive adaptation to frugivory, compared to non-volant animals, flight allows birds and bats to more easily obtain patchilydistributed but energy-rich food sources in difficult to access and widely dispersed locations, including fruits (Benson et al., 2018, 2014a; Maurer, 1998), and may in part explain the high prevalence of frugivory (and especially the consumption of small fruits such as berries) among extant birds compared to most other tetrapod groups (Tiffney, 2004, 1992).

Although true fruits are only present in angiosperms, seed ferns and gymnosperms evolved functionally analogous fleshy-coated propagules (arils) much earlier (Herendeen et al., 2017). Such structures represent specialisations for animal-mediated seed dispersal. Early fruit-producing angiosperms were present by the Early Cretaceous (Eriksson et al., 2000b), alongside multiple groups of aril-producing gymnosperms including cycadales, ginkgoales and gnetales (Tiffney, 2004, 1986; Wu, 1999) \pm which are also present in Jehol Biota (Leng and Friis, 2003; Sun et al., 2001). The alimentary contents preserved in Jeholornis were preliminarily described as ginkgo-like seeds (Zhou and Wu, 2006), but have not been confidently identified with detailed comparisons with all the potential Early Cretaceous fruits/arils. In addition, a diversity of ingested seed morphotypes have been documented among these alimentary contents $2 \partial \& R Q Q R \cup H A W, 2018)$. Therefore, considering that early birds such as those from the Jehol Biota would encounter both gymnosperms and angiosperms, we suggest that during the origin of frugivory among birds, early frugivorous 
birds were likely to be opportunistic and targeted small, fleshy propagules from both groups, rather than being $\mu P Q R V S H U P V S H F L D$ O.LVWV $\partial$

Given the importance of frugivorous birds today as agents of seed dispersal (Pejchar et al., 2008; Sekercioglu, 2006; Tiffney, 2004), the ancient origin of frugivory in birds signifies the origin of an important component of modern-like biotic dispersal systems, providing new opportunities for co-evolutionary mutualisms. The occurrence of specialised seed-dispersal by animals during the Early Cretaceous has previously been proposed indirectly, based on the presence of aril-producing gymnosperm and early fruit-producing angiosperms (Eriksson, 2008; Eriksson et al., 2000a). However, the identification of these frugivores has been uncertain and frugivory was almost unmentioned in the recent review of early bird diets (Miller and Pittman, 2021). Strong indications for at least seasonal frugivory in Jeholornis provides direct evidence of this for the first time.

Fossil birds have low preservation potential and are known primarily from sites of exceptional preservation. Outside of the Jehol Biota, the fossil record of early birds is poorlysampled, both in space and time. However, evidence from less complete fossil remains suggests that birds had a wide geographic distribution by the Early Cretaceous (Chiappe and Witmer, 2002; Close et al., 2009), suggesting a K LG GHQ JW D [R Q,RaRb fmost likely ecological, diversity of Mesozoic birds. Diversification of birds therefore may explain, at least in part, the evolutionary expansion of fruit abundance, especially angiosperm fruits, that occurred through the Cretaceous (Eriksson, 2008; Eriksson et al., 2000a). Direct evidence for the diet of extinct species is rare. However, evidence for fruit consumption in Jeholornis indicates the potential for either opportunistic or specialised frugivory among early birds in general. It therefore increases support for the hypothesis that bird-plant interactions played a role in the Cretaceous Terrestrial Revolution (Tiffney, 2004). Specifically, the occurrence of frugivory in one of the earliest-diverging bird lineages raises the possibility of synergistic 
343 diversification, with birds enabling seed dispersal for plants, and obtaining a rich energy

344 resource in return. New discoveries and comparative analyses are required to further test this

345 hypothesis, by insights into the ecologies of more early bird species, and the potential role of

346 the birds during the transition from gymnosperm- to angiosperm- dominated floras.

\section{$348 \quad$ Materials and Methods}

Taxonomy of Jeholornis STM 3-8

Jeholornis STM 3-8 was collected from the Jiufotang Formation ( 120 Ma) (He et al., 2004) at the Dapingfang locality in Chaoyang, Liaoning province, preserving a complete and mostly articulated skull, and a few postcranial elements. This new specimen is tentatively assigned to Jeholornis prima based on the presence of the following features: relatively robust mandible with three rostrally restricted teeth; edentulous and robust premaxilla; maxilla lacking teeth in the caudal portion; long bony tail consisting of more than 20 caudal vertebrates. This specimen could be distinguished from Jeholornis palmapenis by its flattened dorsal margin of ilium, compared to the strongly convex condition in J. palmapenis $2 \partial \&$ RQQRUHWDO . The validity of another recently reported jeholornithiformes, Kompsornis longicaudus (Wang et al., 2020) needs more discussions since only one specimen is used to erect it, while no detailed comparisons have been done to the numerous specimens which have been assigned to Jeholornis before. In addition, the parts bearing key

362 features listed in (Wang et al., 2020) such as pectoral girdle and sternum, are not preserved in

363 STM 3-8. However, some characters such as the relatively pointed rostral tip of the mandible of Kompsornis still tentatively indicate that STM 3-8 may be distinguished different from it. 
beam energy of $70 \mathrm{keV}$, a sample-to-detector distance of $200 \mathrm{~mm}$. As the height of the

specimen exceeded the detector field-of-view, the specimen was aligned axially relative to the beam and imaged using seven consecutive scans. The raw 16-bit radiographic series were

(Gureyev et al., 2011).

The 3D reconstructions (Figure 1A, B) and the fixing of 3D models (Figure 1C, D) were created and completed with the software Mimics and 3-matic (version 16.1). The mandible model of Jeholornis STM 3-8 was reconstructed for the GMM analysis (Figure 1H) by the following steps; the crashed left splenial was replaced by the mirrored right splenial; the breakage through the left dentary and surangular was joined together; second left dentary tooth was replaced by the mirrored right counterpart with better preservation; all the left dentary teeth were slightly relocated according to the morphology of the alveoli; the fixed left mandible was then mirrored to create the right half; the two sides were joined together, with the angle between them determined by the width of the braincase. The $3 \mathrm{D}$ models of the cranial elements of Jeholornis STM 3-8 were reassembled (Figure 1C, D) by the following steps: all the left elements with better preservation were mirrored to create the right half, except for the pterygoid, for which the better-preserved right one was used as the reference; all the elements were relatively relocated to build a complete skull according to their articulations and anatomical geometry. Since most elements are only slightly dislocated with the articulations/articulation facets preserved, this reassembled model is largely reliable, with 
the location of the preorbital ossifications being the highest uncertainty. The reassembled cranial model was then used as the reference for the 2D reconstruction of the Jeholornis skull in lateral and ventral views (Figure 1E, F).

\section{GMM analyses}

The dataset incorporates Jeholornis and 160 extant bird species representing 111 families and 36 orders in our 3D mandible analysis, with additional Mesozoic theropods in 2D skull analysis including: Sinornithosaurus (Dromaeosauridae) (Xu and Wu, 2001), Linheraptor (Dromaeosauridae) (Xu et al., 2015), Dilong (Tyrannosauroidea) (Xu et al., 2004)' Archaeopteryx (non-Ornithothoraces Aves) (Rauhut, 2014), Sapeornis (non-

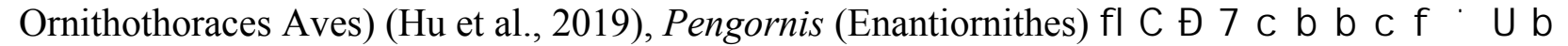
2011) and Ichthyornis (Ornithuromorpha) (Field et al., 2018). We note that the 2D cranial reconstruction of Pengornis is less reliable among those Mesozoic samples due to the comparatively poor preservation, but we incorporate it here as it is currently the best representative enantiornithine.

One anatomical landmark and four curves (semi-landmarks) were placed in each mandible in 3D, and five anatomical landmarks and five curves were placed in each cranium in 2D, using Avizo Lite (version 9.2.0). Landmark definitions and descriptions are modified from Bjarnason and Benson, 2021 (Bjarnason and Benson, 2021) (details see Figure 2 figure supplements 1 and Figure 2 - Source data 1\&2). All the digital landmarks and semilandmarks were imported into R (version 3.6.0) for further analyses. A GPA was performed RQD 0 OODQGPDUNVXVLQJWKHJSDJHQIXQFWLRQIURPWKH5SDFNDJH \HRPRUSK \#NRURW translate, and scale landmark configurations to unit centroid size \$GDPVDQG 2W iUROD(\&DVWLOOR 2013; Goodall, 1991; Rohlf and Slice, 1990). To visualize the multivariate ordination of the aligned Procrustes coordinates, a PCA was performed afterward using plotTangentSpace() 
IURP ㄱR RPRUSK ¥FKHVKDSHY DULDWLRQVRIERWK'PDQGLEOHDQG'VNXOODORQJ GLIIHUH axes ZHUHY LVXDOL]HGXVLQJSORW 5HI7R 7DUJHWIUR.P $\geqslant$ HRPRUSK $¥$

The ecological information including diet categories and foraging strategies of modern birds were modified from Wilman et al., 2014 (Wilman et al., 2014). The diets of birds were originally assigned to five categories in: (1) Plant and Seeds; (2) Fruits and Nectar; (3) Invertebrates; (4) Vertebrates and Fish and Carrion; and (5) Omnivore (Wilman et al., 2014). Based on our focal goal and information from Birds of the World (BOW) (Billerman et al., 2020), those categories were either split or merged to form five new categories: (1) Seedcrackers (parrots): Psittaciformes; (2) Seed-crackers (passerines): mostly finches including Fringillidae, Thraupidae and Sylviidae, and some other granivorous passerines; (3) Seedgrinders: galliforms and members of Columbidae, Anatidae, Alaudidae, Odontophoridae, Tinamidae, Pedionomidae and Pteroclidae; (4) Fruit eaters: members of Paradisaeidae, Phasianidae, Calyptomenidae, Capitonidae, Coliidae, Musophagidae, Cracidae, Megalaimidae, Opisthocomidae, Pipridae, Psophiidae, Columbidae, Ramphastidae, Cotingidae, Tityridae and Trogonidae, as well as the frugivorous parrot Psittrichas fulgidus (Pesquet's Parrot); (5) Other diets (such as other herbivores, carnivores and omnivores). Among them, the diets of three modern species were modified according to BOW (Billerman et al., 2020): Anas discors modified to be $\supseteq$ Seed-grinders $¥$ from $\geqq 0$ mnivore $¥ K L F K L V D O V R$ consistent with other anatids; Psittacus erithacus modified to be $\geq$ Seed-crackers (parrots) $¥$ from $\geq$ ) ruitV D Q G 1 HFW Bible it has the ability and occasionally does crack and eat seeds;

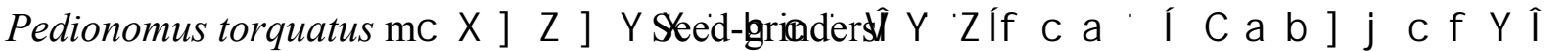
includes $30 \%$ of seeds and its complexity is discussed in the Results part. The modified diet categories were used to group the samples in the PCA results (Figure 2).

\section{Detailed descriptions of the alimentary contents in modern birds}



revealed along the alimentary tract of our sample, each including four intact, unabraded seeds in a regular configuration, as well as another kind of disc-shaped seeds, and no gastroliths are preserved (Figure 4A; Figure 4 - figure supplements 1A). Another frugivore Bombycilla garrulus (Bohemian waxwing, Figure 4 - figure supplements 1C, D) was also sampled, and the same situation of the contents is revealed as in M. comrii. All the seeds preserved through its alimentary tract including crop, stomach and intestines are intact, and more sparsely located than in the seed-grinders and seed-crackers that we sampled.

2. Seed-cracking parrots: Conuropsis carolinensis (Carolina parakeet, Figure 4E), a parrot, is a specialized seed-cracker using beak to de-husk the seeds (Billerman et al., 2020). The alimentary tract of this sample contains a proportionally small bolus of highly fragmented seeds with original shapes impossible to determine, and very few small and sparse stones.

3. Seed-cracking passerines: Geospiza fuliginosa (Small ground-finch, Figure 4D, Figure 4 - figure supplements 1E) is half a seed-cracker and half a seed-grinder, and has a diet mostly consisting of small seeds (Billerman et al., 2020). The crop contents of this sample consist of seeds with almost intact configuration, whereas those in the stomach are highly fragmentary along with lots of large gastroliths. We then sampled another seed cracking

461 passerine Calcarius lapponicus (Lapland longspur, Figure 4 - figure supplements 1F), and 462 found the same situation of the contents as in G. fuliginosa.

4. Seed-grinding granivores: Ectopistes migratorius (Passenger pigeon, Figure 4C,

464 Figure 4 - figure supplements 1B), a seed-specialist pigeon, is a seed-grinder that entirely uses gastroliths to crack the seeds (Billerman et al., 2020). Its crop contains numerous, well- 
in C. carolinensis and G. fuliginosa, together with two large, round gastroliths. Another

468

469

470

471

472

473

474

475

476

477

478

479

480

481

482

483

484

485

486

487

488

489

490

491

representative, Pedionomus torquatus (Plains-wanderer, Figure 4B, Figure 4 - figure

supplements 2A-D) is a general, small-sized seed-grinder. The seeds preserved in the alimentary tract of $P$. torquatus are comparatively more intact than those in other seed specialists such as parrots, pigeons and finches, but many seeds show partial breakages and the gastroliths they contained are much smaller. This indicates that $P$. torquatus might utilize another strategy of abrasion to digest the seeds rather than entirely fragmentation. To test this interpretation, we sampled another seed generalist, Thinocorus rumicivorus (Least seedsnipe, Figure 4 - figure supplements 2E, F). The seed remains are in the same condition as in $P$. torquatus \pm not fragmentary but abraded with partial breakages, along with small gastroliths, confirming the strategy used by those general seed-grinders.

\section{Acknowledgments}

We acknowledge Dahan Li and Wei Gao (Institute of Vertebrate Paleontology and Paleoanthropology, Chinese Academy of Sciences) for specimen preparation and photography; Matt White and Gabriele Sansalone (University of New England, Australia) for help with CT scanning and discussions; Anton Maksimenko for technical assistance with the synchrotron imaging; Andrew Orkney and Duhita Naware (University of Oxford, UK) for discussions; and Zhixin Han for ecological reconstruction illustrations. This research was supported by a Postdoctoral Research Fellowship from the University of New England; Anne Sleep Award from the Linnean Society of London; project ZR2020MD026 supported by Shandong Provincial Natural Science Foundation, China; Linyi Key Research and Development Project 2020ZX028; and the National Natural Science Foundation of China grant 41688103, 41402017, 42002016. Access to the AustralLDQ6IQFK URWUR QDV ,PDJLQJ DQG Medical Beamline was granted under proposal M13126. 


\section{Data and materials availability}

494

The new specimen reported here (Jeholornis STM 3-8) is housed and available for future

researchers to check at Shandong Tianyu Museum of Nature, China. The original CT

496

scanning slices and segmented STL files of Jeholornis STM 3-8 and involved modern birds,

497

and the alimentary contents of selected modern birds are available in Morphosource

498

(https://www.morphosource.org/projects/0000C1212?locale=en;

499

https://www.morphosource.org/projects/00000C420;

https://www.morphosource.org/projects/0000C1080?locale=en). Other data that support this

501

502

503

504

505

506

507

508

509

510

511

512

513

514

515

516

517

518

519

520

study are available in Figshare (https://figshare.com/s/6a96e1338cadd70f9723), including the rotating videos of the original/reassembled cranial 3D models of Jeholornis STM 3-8 and the 3D models of the alimentary contents of selected modern birds, and the landmark data and taxa lists used in GMM analyses. Further information and requests for resources should be

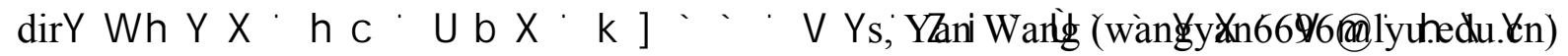
and Han Hu (han.hu@earth.ox.ac.uk).

\section{References}

\$GDPV '\& 2W IUROD (\&DVWL OOR (J HRPRUSKan r package for the collection and analysis

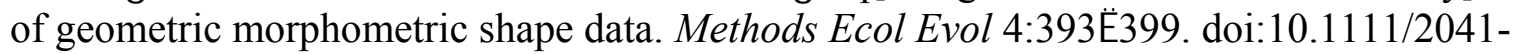
210x.12035

Benson RBJ. 2018. Dinosaur Macroevolution and Macroecology. Annu Rev Ecol Evol Syst

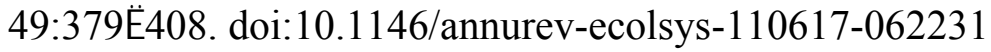

Benson RBJ, Campione NE, Carrano MT, Mannion PD, Sullivan C, Upchurch P, Evans DC. 2014a. Rates of dinosaur body mass evolution indicate 170 million years of sustained ecological innovation on the avian stem lineage. Plos Biol 12:e1001853. doi:10.1371/journal.pbio.1001853

Benson RBJ, Frigot RA, Goswami A, Andres B, Butler RJ. 2014b. Competition and

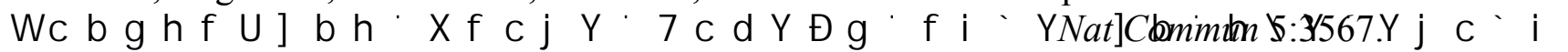
doi:10.1038/ncomms4567 


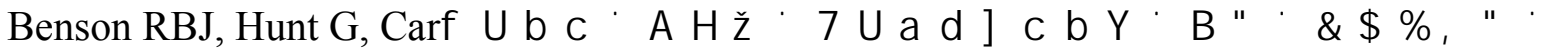
landscape of dinosaur body size evolution. Palaeontology 61:13 \pm 48 . doi:10.1111/pala.12329

Benton MJ. 2010. The origins of modern biodiversity on land. Philosophical Transactions Royal Soc B Biological Sci 365:3667士3679. doi:10.1098/rstb.2010.0269

Billerman SM, Keeney BK, Rodewald PG, Schulenberg TS, editors. 2020. Birds of the World. Ithaca, NY, USA.: Cornell Laboratory of Ornithology.

Bjarnason A, Benson R. 2021. A 3D geometric morphometric dataset quantifying skeletal variation in birds. Morphomuseum 7:e125. doi:10.18563/journal.m3.125

Chiappe LM, Witmer LM. 2002. Mesozoic birds: above the heads of dinosaurs. Berkeley: University of California Press.

Clapham ME, Karr JA. 2012. Environmental and biotic controls on the evolutionary history of insect body size. Proc National Acad Sci 109:10927 \pm 10930 . doi:10.1073/pnas.1204026109

Close RA, Vickers-5LFK 37UXV OHU 3\& KLDSSH/022FRQQRU -.5LFK 7+.RRO/ Komarower P. 2009. Earliest Gondwanan bird from the Cretaceous of southeastern Australia. J Vertebr Paleontol 29:616 \pm 619 . doi:10.1671/039.029.0214

Elzanowski A, Wellnhofer P. 1996. Cranial morphology of Archaeopteryx: evidence from the seventh skeleton. J Vertebr Paleontol 16:81£94. doi:10.1080/02724634.1996.10011286

Eriksson O. 2008. Evolution of seed size and biotic seed dispersal in Angiosperms:

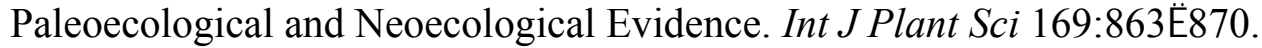
doi:10.1086/589888

Eriksson O, Friis EM, Löfgren. 2000a. Seed size, fruit size, and dispersal systems in Angiosperms from the Early Cretaceous to the Late Tertiary. Am Nat 156:47 \pm 58 . doi:10.1086/303367

Eriksson O, Friis EM, Pedersen KR, Crane PR. 2000b. Seed size and dispersal systems of

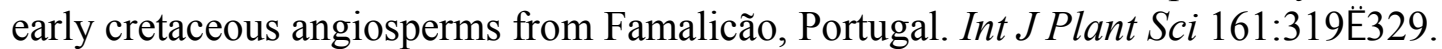
doi: $10.1086 / 314248$

Field DJ, Hanson M, Burnham D, Wilson LE, Super K, Ehret D, Ebersole JA, Bhullar B-AS. 2018. Complete Ichthyornis skull illuminates mosaic assembly of the avian head. Nature 557:96 \pm 100 . doi:10.1038/s41586-018-0053-y

Gionfriddo JP, Best LB. 1996. Grit-use patterns in North American birds: the influence of diet, body size, and gender. The Wilson Bulletin 685 \pm 696 .

Goodall C. 1991. Procrustes methods in the statistical analysis of shape. J Royal Statistical Soc Ser B Methodol 53:285士321. doi:10.1111/j.2517-6161.1991.tb01825.x 
Gureyev TE, Nesterets Y, Ternovski D, Thompson D, Wilkins SW, Stevenson AW, Sakellariou A, Taylor JA. 2011. Toolbox for advanced x-ray image processing 81410B81410B \pm 14 . doi:10.1117/12.893252

He HY, Wang XL, Zhou ZH, Wang F, Boven A, Shi GH, Zhu RX. 2004. Timing of the Jiufotang Formation (Jehol Group) in Liaoning, northeastern China, and its implications. Geophys Res Lett 31:n/a-n/a. doi:10.1029/2004g1019790

Herendeen PS, Friis EM, Pedersen KR, Crane PR. 2017. Palaeobotanical redux: revisiting the age of the angiosperms. Nat Plants 3:17015. doi:10.1038/nplants.2017.15

$+X+2 \partial \&$ RQQRU -.0F'R nald PG, Wroe S. 2020a. Cranial osteology of the Early Cretaceous Sapeornis chaoyangensis (Aves: Pygostylia). Cretaceous Res 113:104496. doi:10.1016/j.cretres.2020.104496

$+X+2 \partial \& R Q Q R U-.:$ DQJ 0:URH6OF'RQD OG 3*E1HZDQDWR PLFDOLQIRUPDWLRQ on the bohaiornithid Longusunguis and the presence of a plesiomorphic diapsid skull in Enantiornithes. J Syst Palaeontol 18:1 \pm 15 . doi:10.1080/14772019.2020.1748133

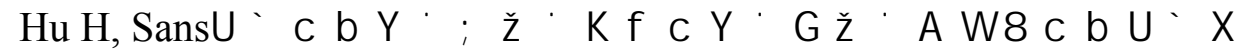
Evolution of the vomer and its implications for cranial kinesis in Paraves. Proc National

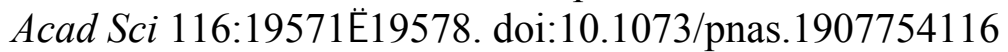

Ksepka DT, Grande L, Mayr G. 2019. Oldest Finch-Beaked Birds Reveal Parallel Ecological Radiations in the Earliest Evolution of Passerines. Curr Biol 29:657-663.e1. doi:10.1016/j.cub.2018.12.040

/HIqY UH8+X '(VFXLOOLp)' INH**RGHIURLW 3\$QHZORQJ (W DLOHGEDVDOELUGIURP

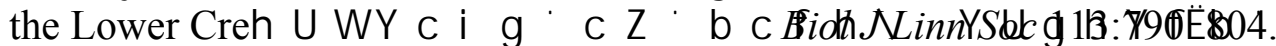
doi:10.1111/bij.12343

Leng Q, Friis EM. 2003. Sinocarpus decussatus gen. et sp. nov., a new angiosperm with basally syncarpous fruits from the Yixian Formation of Northeast China. Plant Syst Evol 241:77士88. doi:10.1007/s00606-003-0028-8

Lloyd GT, Davis KE, Pisani D, Tarver JE, Ruta M, Sakamoto M, Hone DWE, Jennings R, Benton MJ. 2008. Dinosaurs and the Cretaceous Terrestrial Revolution. Proc Biological

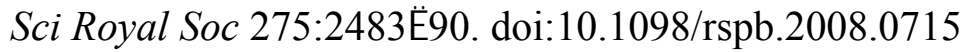

Maurer B a. 1998. The evolution of body size in birds. II. The role of reproductive power. Evol Ecol 12:935 \pm 944 . doi:10.1023/a:1006564105504

Mayr G, Kaye TG, Pittman M, Saitta ET, Pott C. 2020. Reanalysis of putative ovarian follicles suggests that Early Cretaceous birds were feeding not breeding. Sci Rep 10:19035. doi:10.1038/s41598-020-76078-2

Mayr G, Pohl B, Hartman S, Peters DS. 2007. The tenth skeletal specimen of Archaeopteryx. Zool J Linn Soc-lond 149:97£1 16. doi:10.1111/j.1096-3642.2006.00245.x 
605

606

607

608

609

610

611

612

613

614

615

616

617

618

619

620

621

622

623

624

625

626

627

Meij MAA van der, Bout RG. 2008. The relationship between shape of the skull and bite force in finches. $J$ Exp Biol 211:1668 \pm 1680 . doi:10.1242/jeb.015289

Miller CV, Pittman M. 2021. The diet of early birds based on modern and fossil evidence and a new framework for its reconstruction. Biol Rev. doi:10.1111/brv.12743

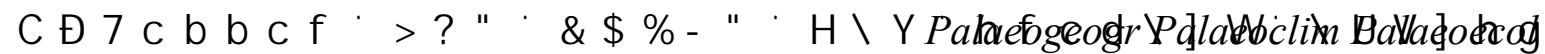
513:178 \pm 195 . doi:10.1016/j.palaeo.2018.03.006

$2 \partial \& R Q Q R U-. \& K L D S S H / 0 \$ U H Y L V L R Q R I H Q D Q W L R U 1$ Qhel/Aves: Ornithothoraces) skull morphology. J Syst Palaeontol 9:135 \pm 157 . doi:10.1080/14772019.2010.526639

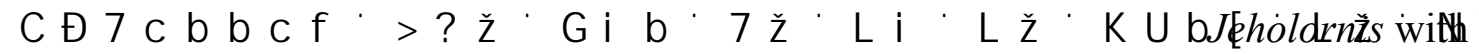

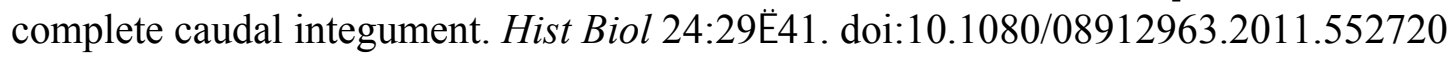

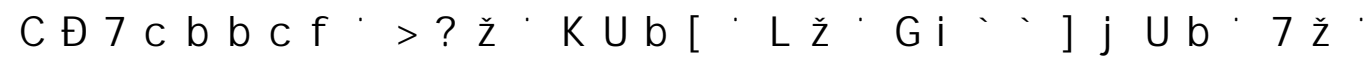
report of gastroliths in the Early Cretaceous basal bird Jeholornis. Cretaceous Res 84:200ஹ208. doi:10.1016/j.cretres.2017.10.031

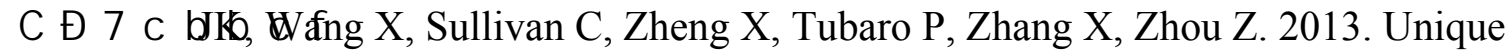
caudal plumage of Jeholornis and complex tail evolution in early birds. Proc National Acad Sci 110:17404 \pm 17408 . doi:10.1073/pnas.1316979110

$2 \partial \& R Q Q R U-.=K R X=7 K H H Y R O X W L R Q R$ f the modern avian digestive system: insights from paravian fossils from the Yanliao and Jehol biotas. Palaeontology 63:13 \pm 27. doi:10.1111/pala.12453

Pejchar L, Pringle RM, Ranganathan J, Zook JR, Duran G, Oviedo F, Daily GC. 2008. Birds as agents of seed dispersal in a human-dominated landscape in southern Costa Rica. Biol Conserv 141:536 \pm 544 . doi:10.1016/j.biocon.2007.11.008

Piersma T, Koolhaas A, Dekinga A. 1993. Interactions between stomach structure and diet choice in shorebirds. Auk 110:552 \pm 564 . doi:10.2307/4088419

Prum RO, Berv JS, Dornburg A, Field DJ, Townsend JP, Lemmon EM, Lemmon AR. 2015. A comprehensive phylogeny of birds (Aves) using targeted next-generation DNA sequencing. Nature 526:569 \pm 573 . doi:10.1038/nature15697

Rauhut OWM. 2014. New observations on the skull of Archaeopteryx. Paläontologische Zeitschrift 88:211+221. doi:10.1007/s12542-013-0186-0

Rauhut OWM, Foth C, Tischlinger H. 2018. The oldest Archaeopteryx (Theropoda: Avialiae): a new specimen from the Kimmeridgian/Tithonian boundary of Schamhaupten, Bavaria. Peerj 6:e4191. doi:10.7717/peerj.4191

Rohlf FJ, Slice D. 1990. Extensions of the procrustes method for the optimal superimposition of landmarks. Syst Zool 39:40. doi:10.2307/2992207

Sekercioglu CH. 2006. Increasing awareness of avian ecological function. Trends Ecol Evol 21:464 \pm 471 . doi:10.1016/j.tree.2006.05.007 
635

636

637

638

639

640

641

642

643

644

645

646

647

648

649

650

651

652

653

654

655

656

657

658

659

660

661

662

663

Soons J, Genbrugge A, Podos J, Adriaens D, Aerts P, Dirckx J, Herrel A. 2015. Is beak mRUSK RORJ \L Q' DUZLfQakes tuned to loading demands? Plos One 10:e0129479. doi:10.1371/journal.pone.0129479

Soons J, Herrel A, Genbrugge A, Aerts P, Podos J, Adriaens D, Witte Y de, Jacobs P, Dirckx

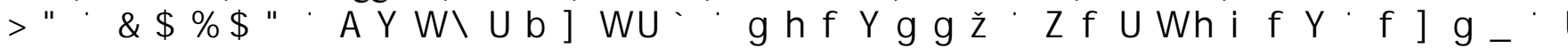
(Geospiza). Philosophical Transactions Royal Soc B Biological Sci 365:1093 \pm 1098 . doi:10.1098/rstb.2009.0280

Sun G, Zheng S, Dilcher D, Wang Y, Mei S. 2001. Early angiosperms and their associated plants from Western Liaoning, China. Shanghai: Science and Technology Education Publishing House.

Tiffney BH. 2004. Vertebrate dispersal of seed plants through time. Ecol Evol Syst 35:1+29. doi:10.1146/annurev.ecolsys.34.011802.132535

Tiffney BH. 1986. Evolution of seed dispersal syndromes according to the fossil record In: Murray DR, editor. Seed Dispersal. Sydney: Academic Press. pp. 273 \pm 305 .

Tiffney BH. 1992. The role of vertebrate herbivory in the evolution of land plants. Palaeobotanist 41:87 \pm 97 .

Wang M, Hu H. 2017. A comparative morphological study of the jugal and quadratojugal in early birds and their dinosaurian relatives. Anatomical Rec 300:62 \pm 75 . doi:10.1002/ar.23446

Wang M, Stidham TA, Zhou Z. 2018. A new clade of basal Early Cretaceous pygostylian birds and developmental plasticity of the avian shoulder girdle. Proc National Acad Sci 115:201812176. doi:10.1073/pnas.1812176115

Wang M, Zhou Z. 2019. A new enantiornithine (Aves: Ornithothoraces) with completely fused premaxillae from the Early Cretaceous of China. J Syst Palaeontol 17:1 \pm 14 . doi:10.1080/14772019.2018.1527403

Wang X, Huang J, Kundrát M, Cau A, Liu X, Wang Y, Ju S. 2020. A new jeholornithiform exhibits the earliest appearance of the fused sternum and pelvis in the evolution of avialan dinosaurs. J Asian Earth Sci 199:104401. doi:10.1016/j.jseaes.2020.104401

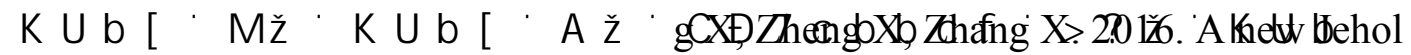
enantiornithine bird with three-dimensional preservation and ovarian follicles. $J$ Vertebr Paleontol 36:e1054496. doi:10.1080/02724634.2015.1054496

Wilman H, Belmaker J, Simpson J, Rosa C de la, Rivadeneira MM, Jetz W. 2014. EltonTraits 1.0: Species-OHY HOIRUDJL QJDWW ULEXWHVRIWK HZRUOGJVELUGVDQGPDPPDOV (FRORJ Archives E095-178. Ecology 95:2027£2027. doi:10.1890/13-1917.1

Wings O. 2007. A review of gastrolith function with implications for fossil vertebrates and a revised classification. Acta Palaeontologica Polonica 52. 
675

676

677

678

679

680

681

682

683

684

685

686

687

688

689

690

691

692

693

694

695

696

697

698

Wu S. 1999. A preliminary study of the Jehol flora from western Liaoning. Palaeoworld $11: 7 \pm 57$.

Xu X, Norell MA, Kuang X, Wang X, Zhao Q, Jia C. 2004. Basal tyrannosauroids from China and evidence for protofeathers in tyrannosauroids. Nature 431:680 \pm 684 . doi: $10.1038 /$ nature 02855

Xu X, Pittman M, Sullivan C, Choiniere JN, Tan Q, Clark JM, Norell MA, Wang S. 2015. The taxonomic status of the Late Cretaceous dromaeosaurid Linheraptor exquisitus and its implications for dromaeosaurid systematics. Vertebrata PalAsiatica 53:29 \pm 62 .

Xu X, Wu X-C. 2001. Cranial morphology of Sinornithosaurus millenii Xu et al. 1999 (Dinosauria: Theropoda: Dromaeosauridae) from the Yixian Formation of Liaoning,

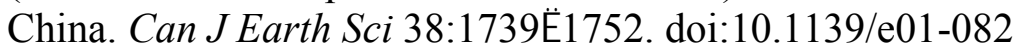

$<$ DQJ $6+H+-L Q$ ) $=K$ DQ J ):X $<<X=/ L 4: D Q J 02 \partial \& R Q Q R U-. ' H Q J \&=K X 5$ Zhou Z. 2020. The appearance and duration of the Jehol Biota: Constraint from SIMS U$\mathrm{Pb}$ zircon dating for the Huajiying Formation in northern China. Proc National Acad Sci 117:14299 \pm 14305 . doi:10.1073/pnas.1918272117

Yu Y, Zhang C, Xu X. 2021. Deep time diversity and the early radiations of birds. Proc National Acad Sci 118:e2019865118. doi:10.1073/pnas.2019865118

Zheng X, Martin LD, Zhou Z, Burnham DA, Zhang F, Miao D. 2011. Fossil evidence of

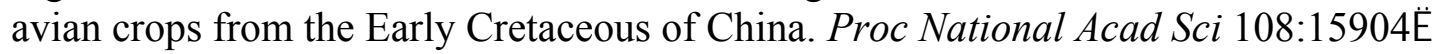
15907. doi:10.1073/pnas.1112694108

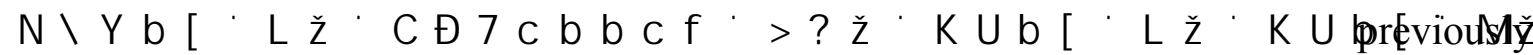
described Jehol bird clarifies early trophic evolution in the Ornithuromorpha. Proc Royal Soc B Biological Sci 285:20172494. doi:10.1098/rspb.2017.2494

$=\mathrm{KHQJ} ; 6 X 00 \mathrm{LY} D Q \& 2 \partial \& \mathrm{RQQRU}-.: \mathrm{DQ}$ J ;:DQJ <=K DQJ ; =K RX =6WUXFWXUH and possible ventilatory function of unusual, expanded sternal ribs in the Early Cretaceous bird Jeholornis. Cretaceous Res 116:104597. doi:10.1016/j.cretres.2020.104597

Zhou Z, Wu X. 2006. The rise of ginkgoalean plants in the early Mesozoic: a data analysis.

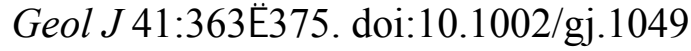

Zhou Z, Zhang F. 2003. Jeholornis compared to Archaeopteryx, with a new understanding of the earliest avian evolution. Naturwissenschaften 90:220+225. doi:10.1007/s00114-0030416-5

Zhou Z, Zhang F. 2002. A long-tailed, seed-eating bird from the Early Cretaceous of China. Nature 418:405 \pm 409 . doi:10.1038/nature00930

\section{Figures}


Figure 1. Jeholornis STM 3-8. (A) Left and (B) right view of the 3D reconstructed model of the skull. (C) Left and (D) ventral view of the reassembled 3D model of the skull. (E) Left

701

702

703

704

705

706

707

708

709

710

711

712

713

714

715

716

717

718

719

720

721

722 and (F) ventral view of the 2D cranial reconstruction. (G) Photograph of the skull. (H) Dorsal view of the reassembled 3D model of the mandible. Abbreviations: 1. premaxilla; 2. nasal; 3 . preorbital ossification; 4. lacrimal; 5. maxilla; 6. jugal; 7. quadratojugal; 8. frontal; 9. braincase; 10. squamosal; 11. postorbital; 12. scleral ring; 13. quadrate; 14. dentary; 15. surangular; 16. angular; 17. splenial; 18. vomer; 19. palatine; 20. pterygoid; 21. potential ectopterygoid. Different bones are indicated by different colours. Scale bar equals $5 \mathrm{~mm}$.

Figure 2. PCA result of 3D mandible shape (A, B) and 2D skull shape (C, D). Different diet categories are indicated by different colours, and key samples are labelled with generic names.

Figure 3. Seeds preserved in the abdominal area of selected $J$. prima specimens. (A) IVPP V13274 (holotype). (B) STM 2-41. (C) Close up image of seeds in IVPP V13274 (A).

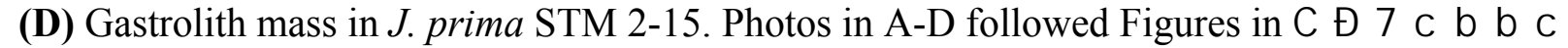

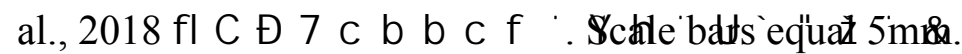

\section{Figure 4. 3D reconstructed seed models preserved in alimentary tract of selected} modern birds. (A) Manucodia comrii (fruit eater). (B) Pedionomus torquatus (seed-grinder). (C) Ectopistes migratorius (seed-grinder). (D) Geospiza fuliginosa (use both seed-cracking and seed-grinding strategies). (E) Conuropsis carolinensis (seed-cracker). Dash-lined boxes indicate local magnifications. Gastroliths are remarkably brighter than other contents in the slices. Red arrows indicate the breakages of seeds in slices, which are difficult to show in the 
reconstructed models. Scale bars equal $5 \mathrm{~mm}$ for the whole models and slices, and $1 \mathrm{~mm}$ for

724

725

726

727

728

729

730

731

732

733

734

735

736

737

738

739

740

741

742

743

744

745

746

747 the magnification boxes.

Figure 2 - figure supplements 1. Landmark and semi-landmark locations in Menura novaehollandiae as an example of modern taxa used in GMM analyses (following Bjarnason and Benson, 2021). Black labels indicate the description names, and blue labels below indicate the names in $\mathrm{R}$.

Figure 2 - figure supplements 2. PCA result of 3D mandible (A, B) and 2D skull shape (C, D) with labels of generic names. Some points in green overlap the points in other colours.

Figure 4 - figure supplements 1 . Scanning slices of the alimentary contents in involved modern bird samples.

Figure 4 - figure supplements 2 . Scanning slices of the alimentary contents in involved modern bird samples. Red arrows indicate the breakages of seeds.

Figure 2 - Source data 1. Descriptions of cranial and upper jaw landmarks and semilandmarks (following Bjarnason and Benson, 2021).

Figure 2 - Source data 2. Descriptions of mandible landmarks and semi-landmarks (following Bjarnason and Benson, 2021).

Figure 4 - Source data 1 . Specimens used in the alimentary content analyses. 

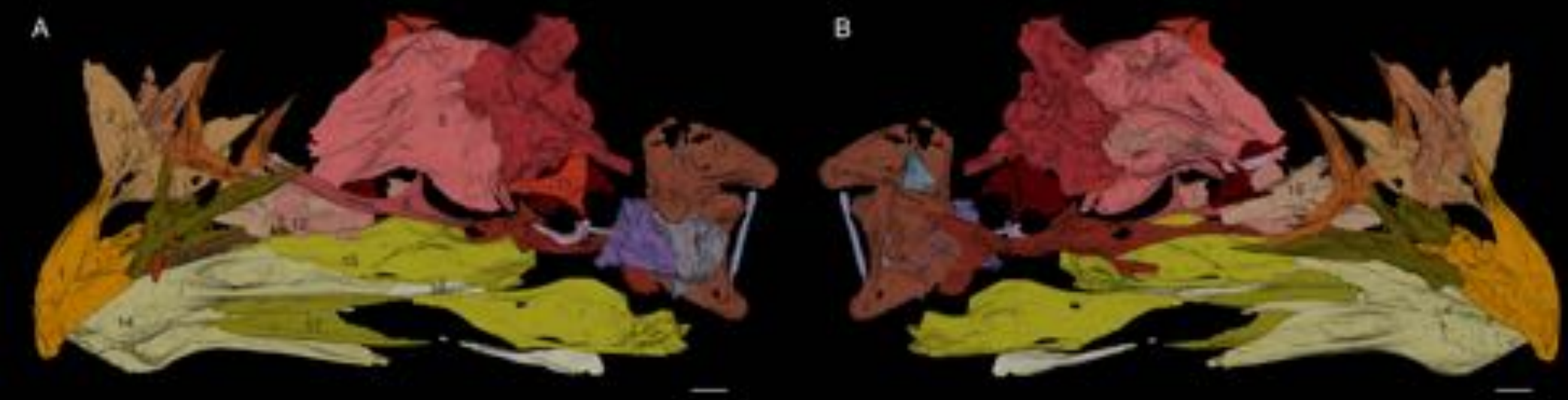

C

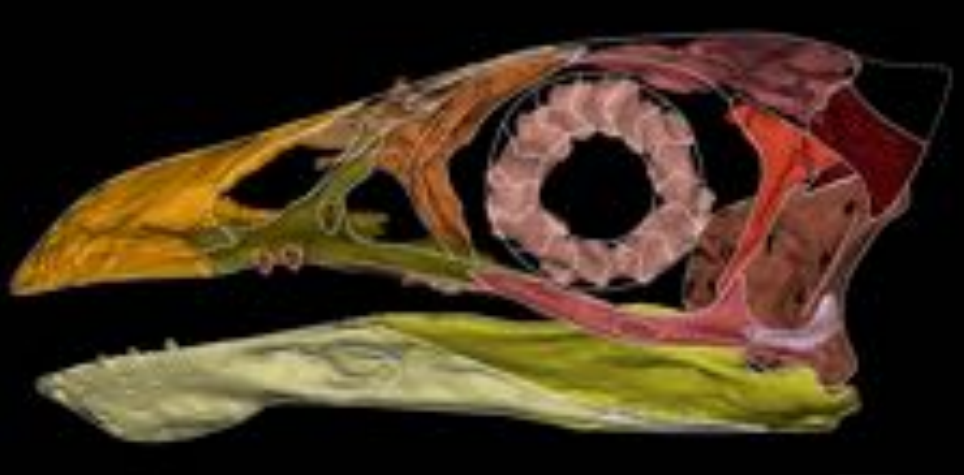

0
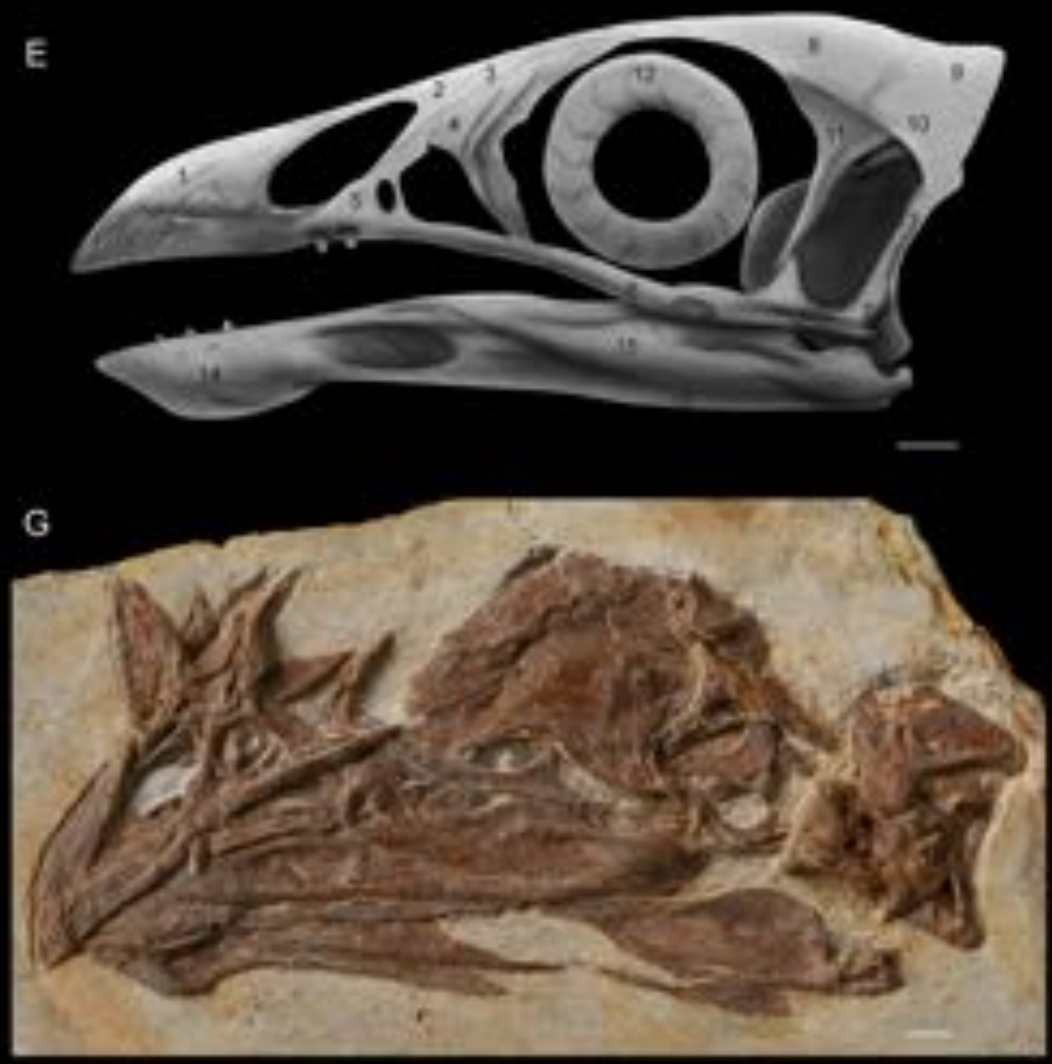

H

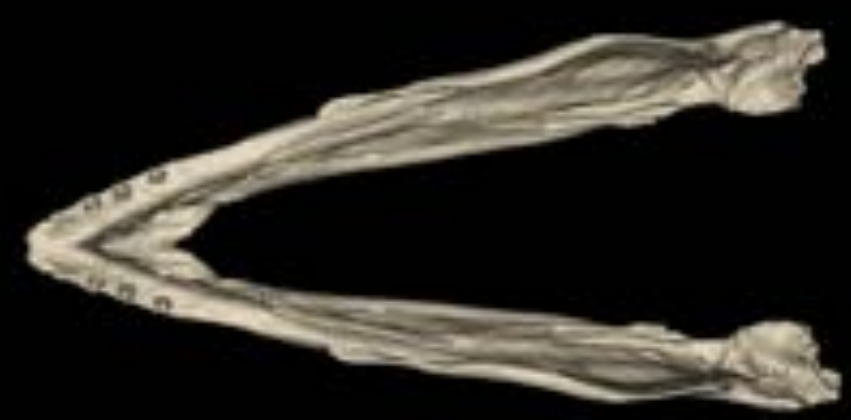




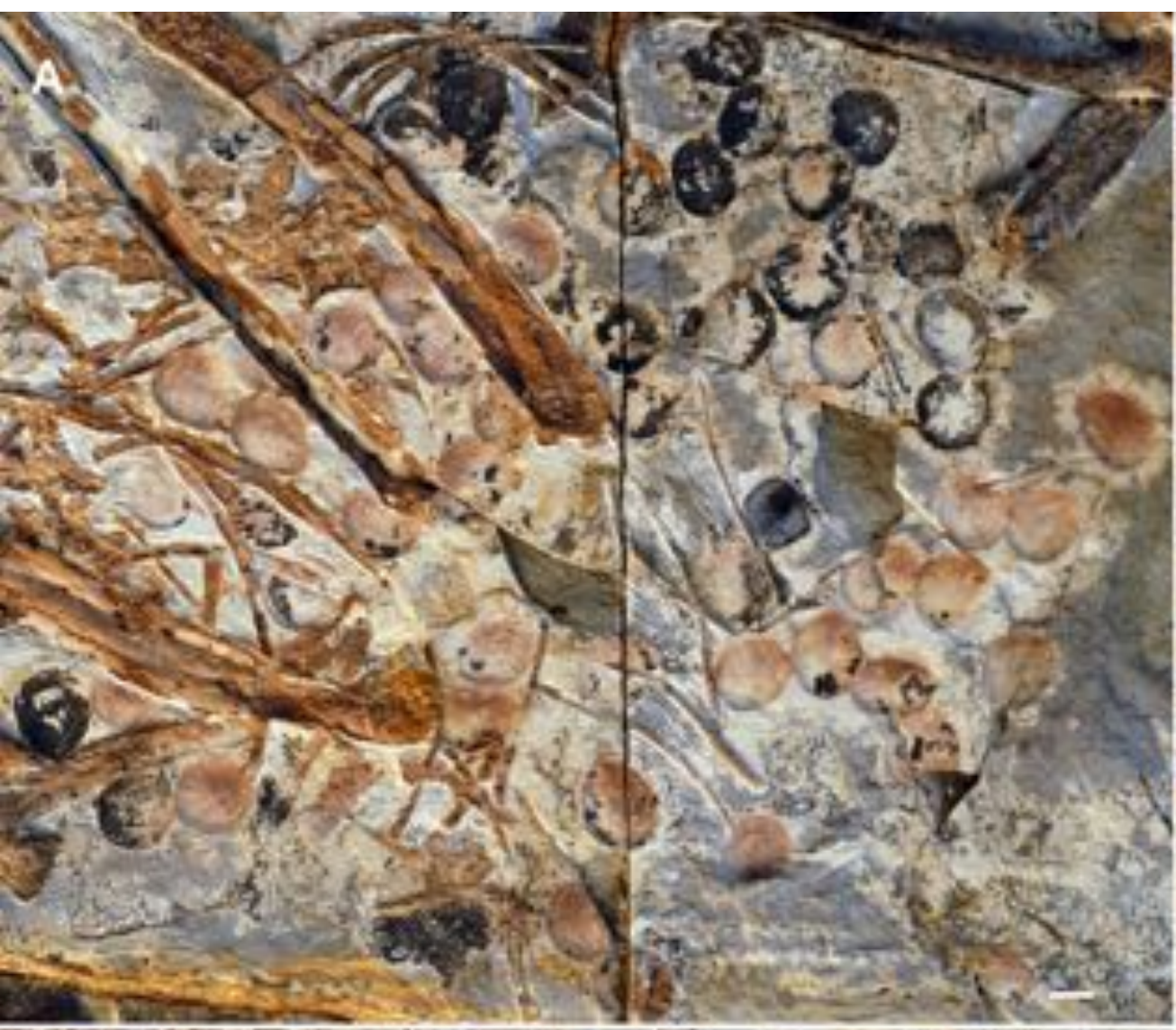

8

\section{(}

\section{s)}

83

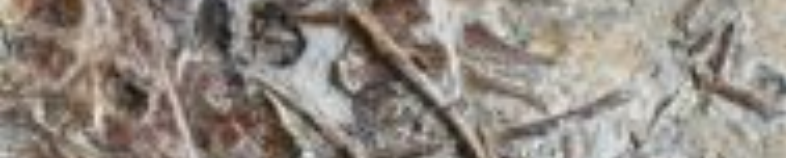
(6) (3)

\section{tons}

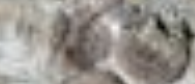

$\lim _{\mathrm{x}} \mathrm{x}$

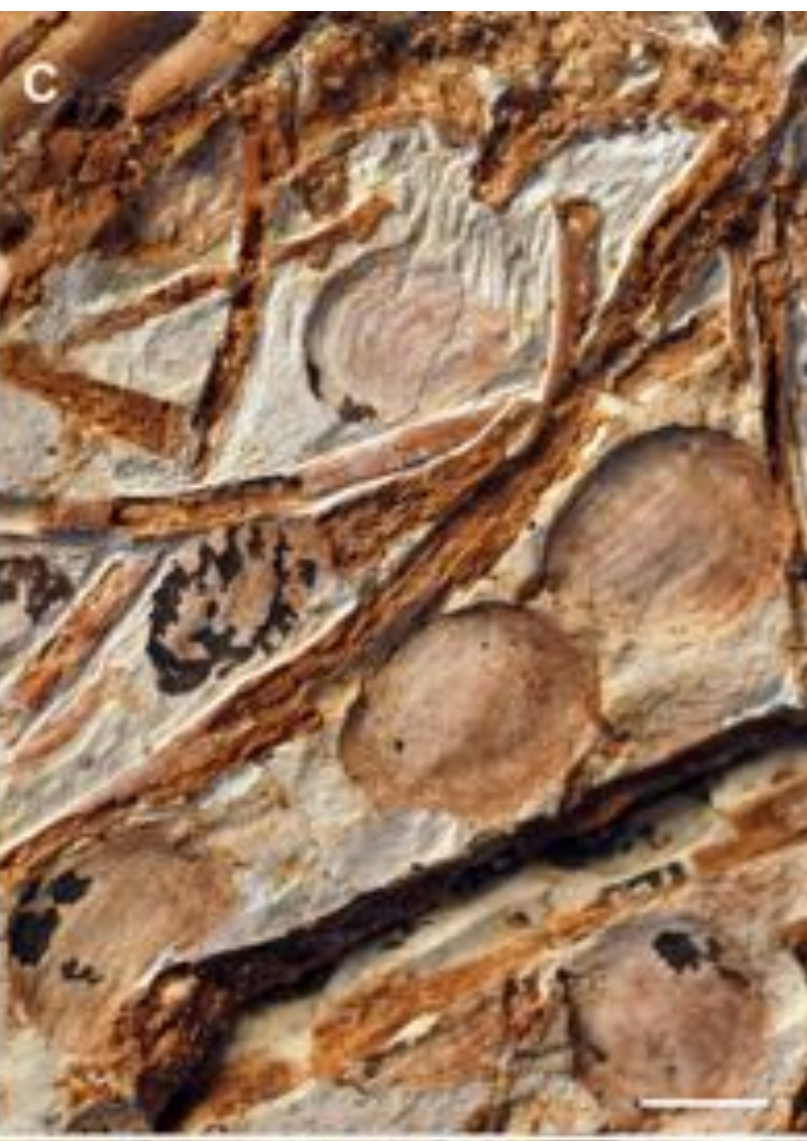

(D)

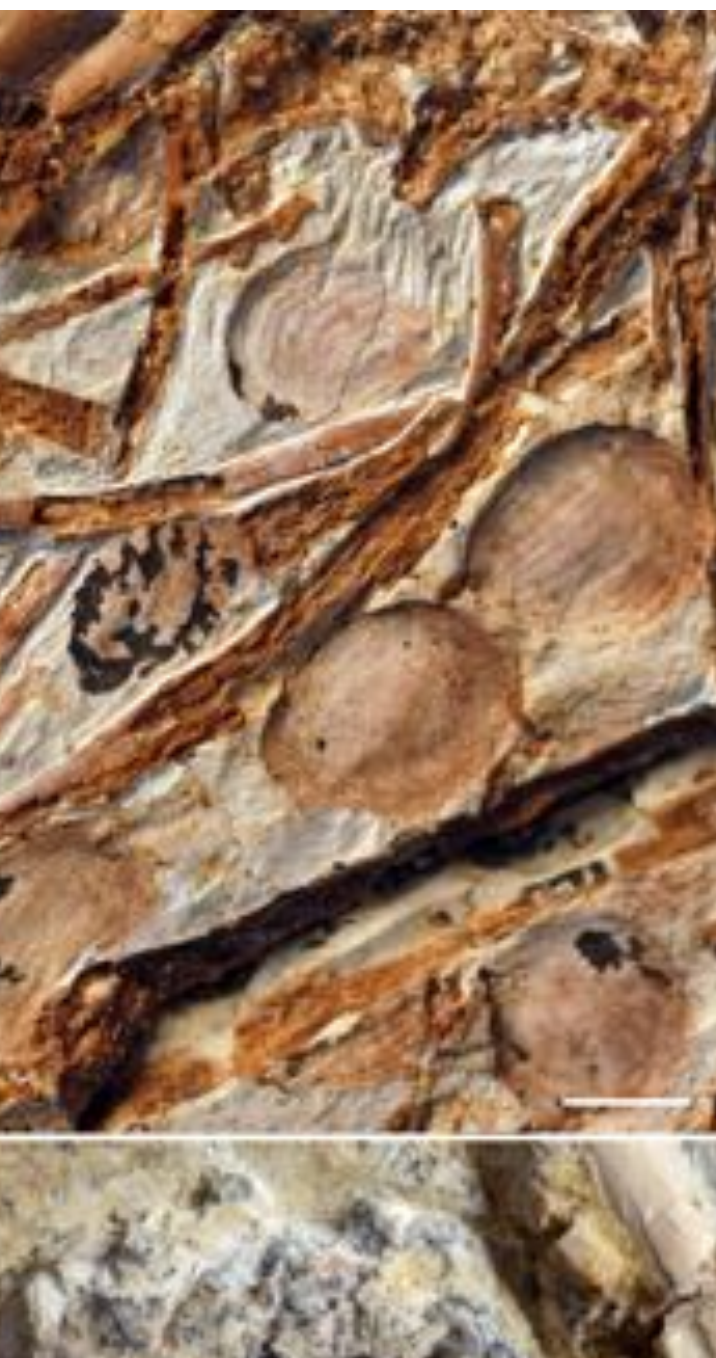

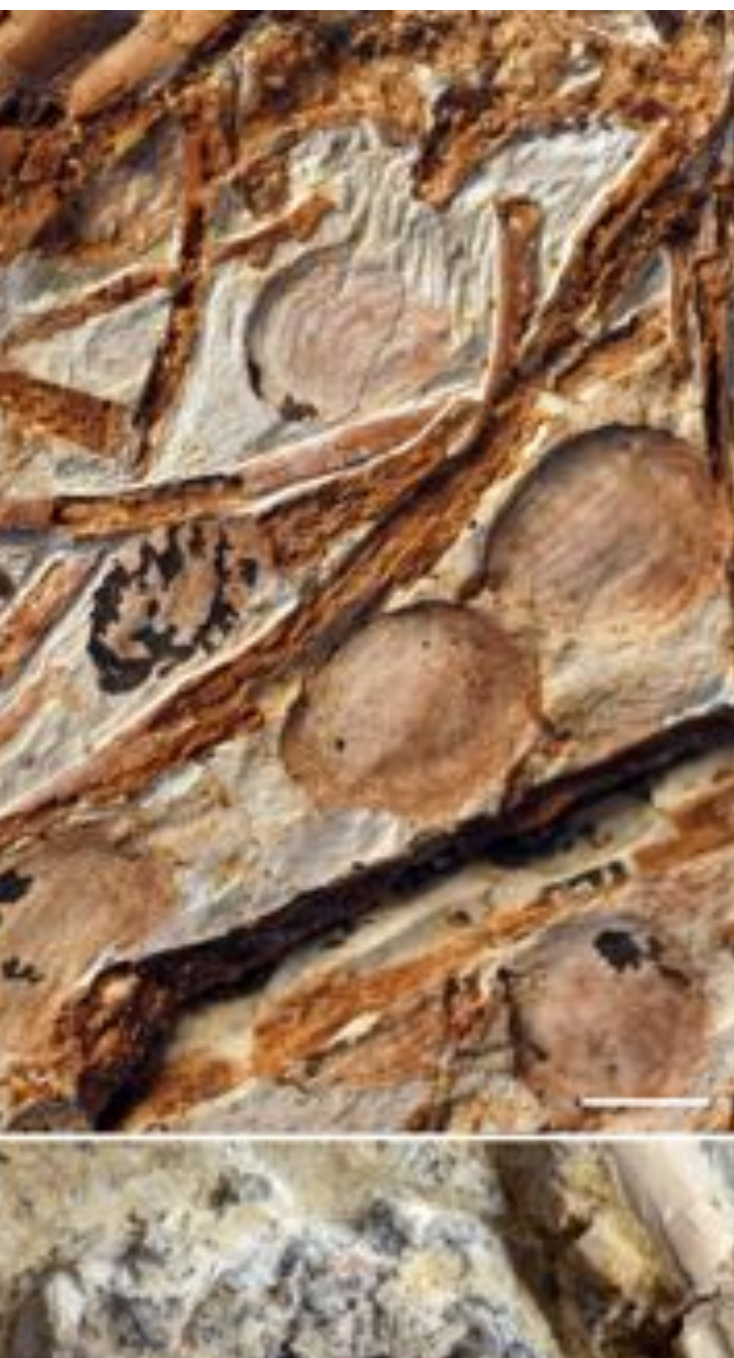

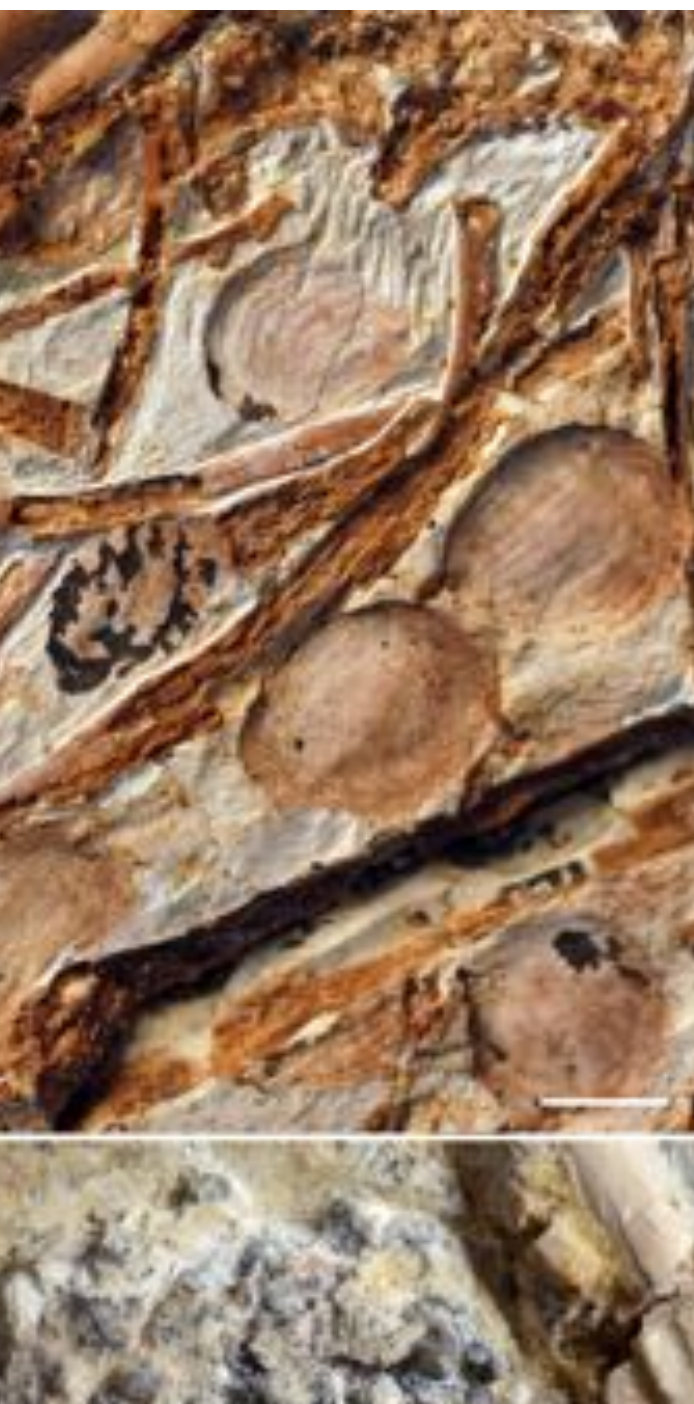

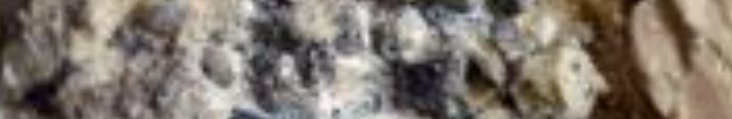

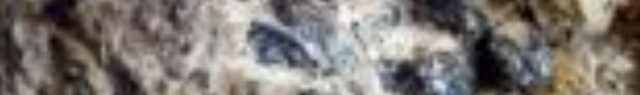

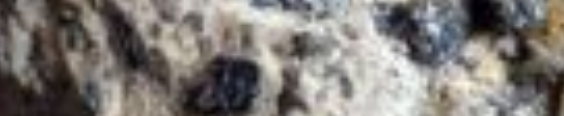

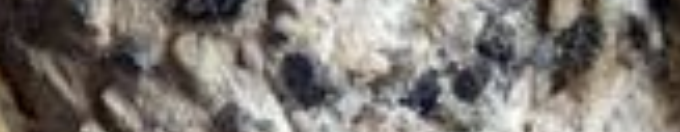

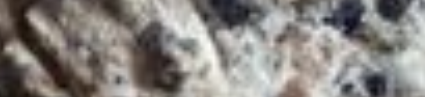

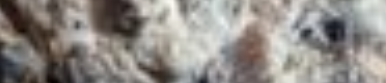

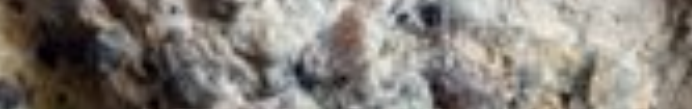

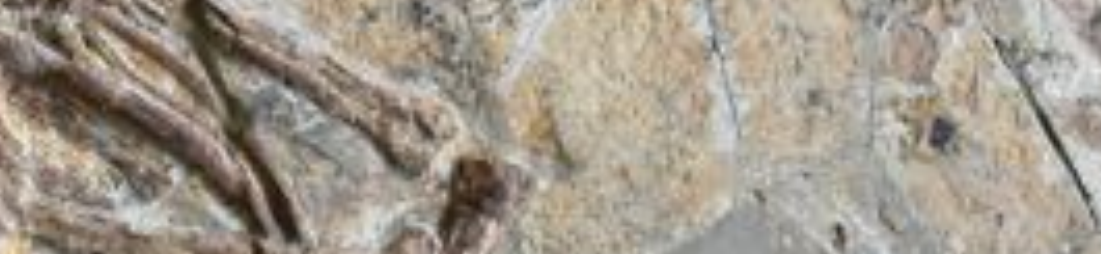


A Manucadia comni
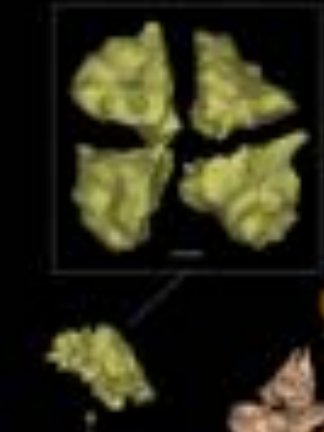

copoostrits

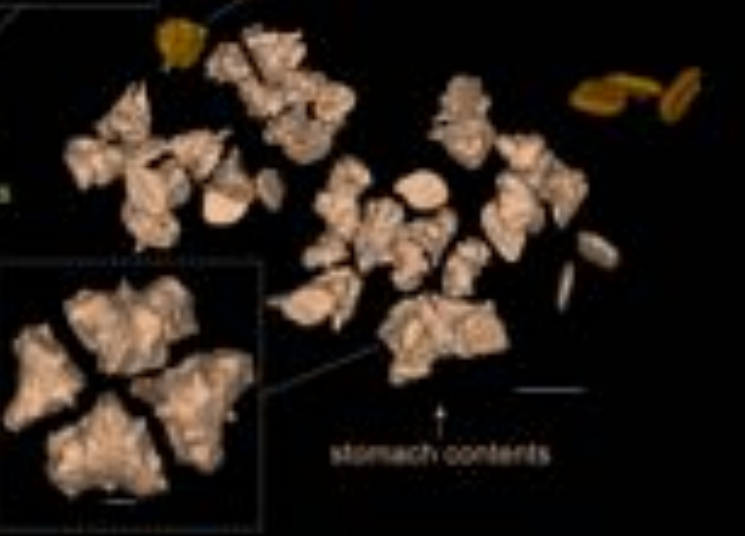

B Pedionomus torguatus
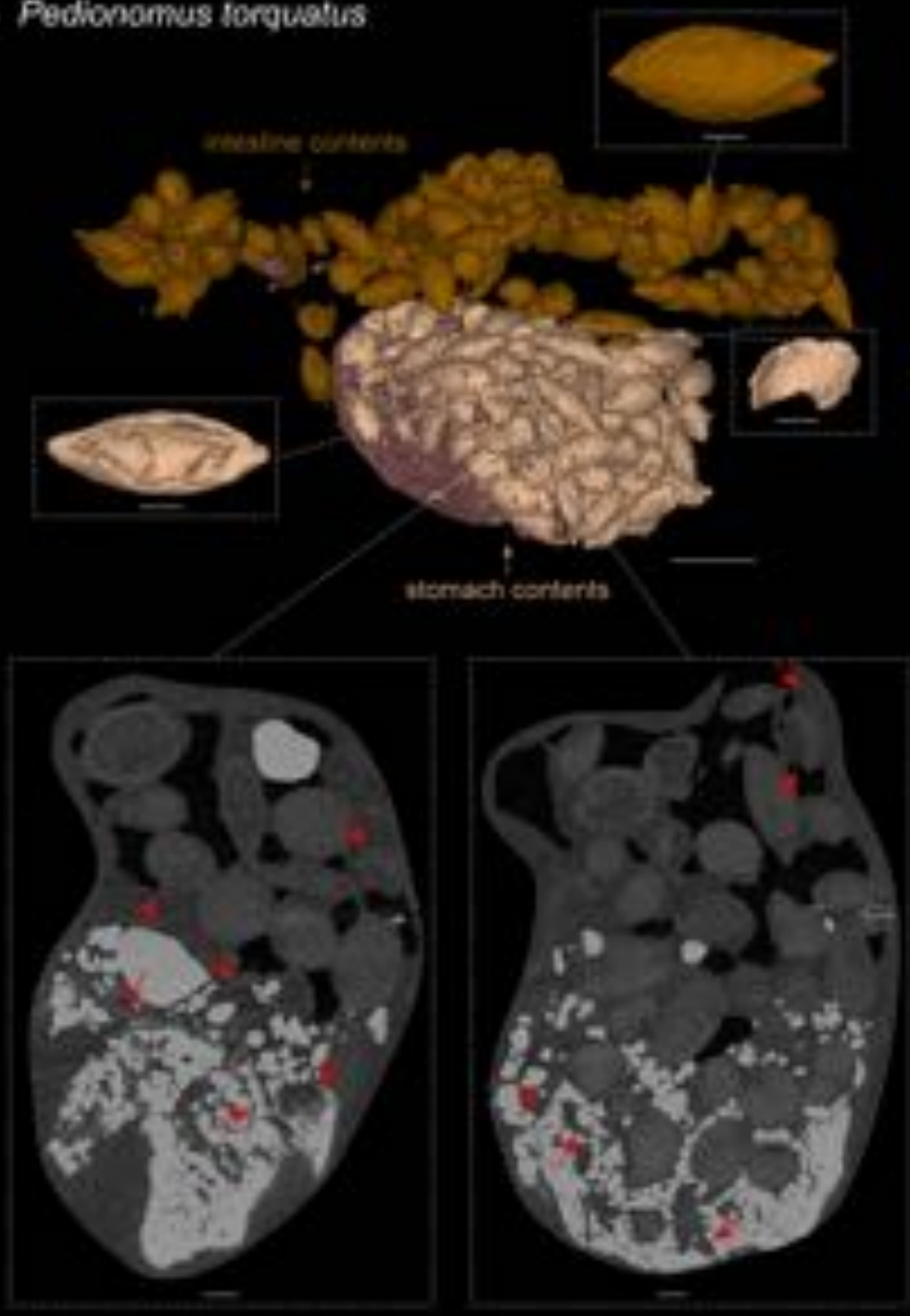

\section{Ectogisfos migratorius}
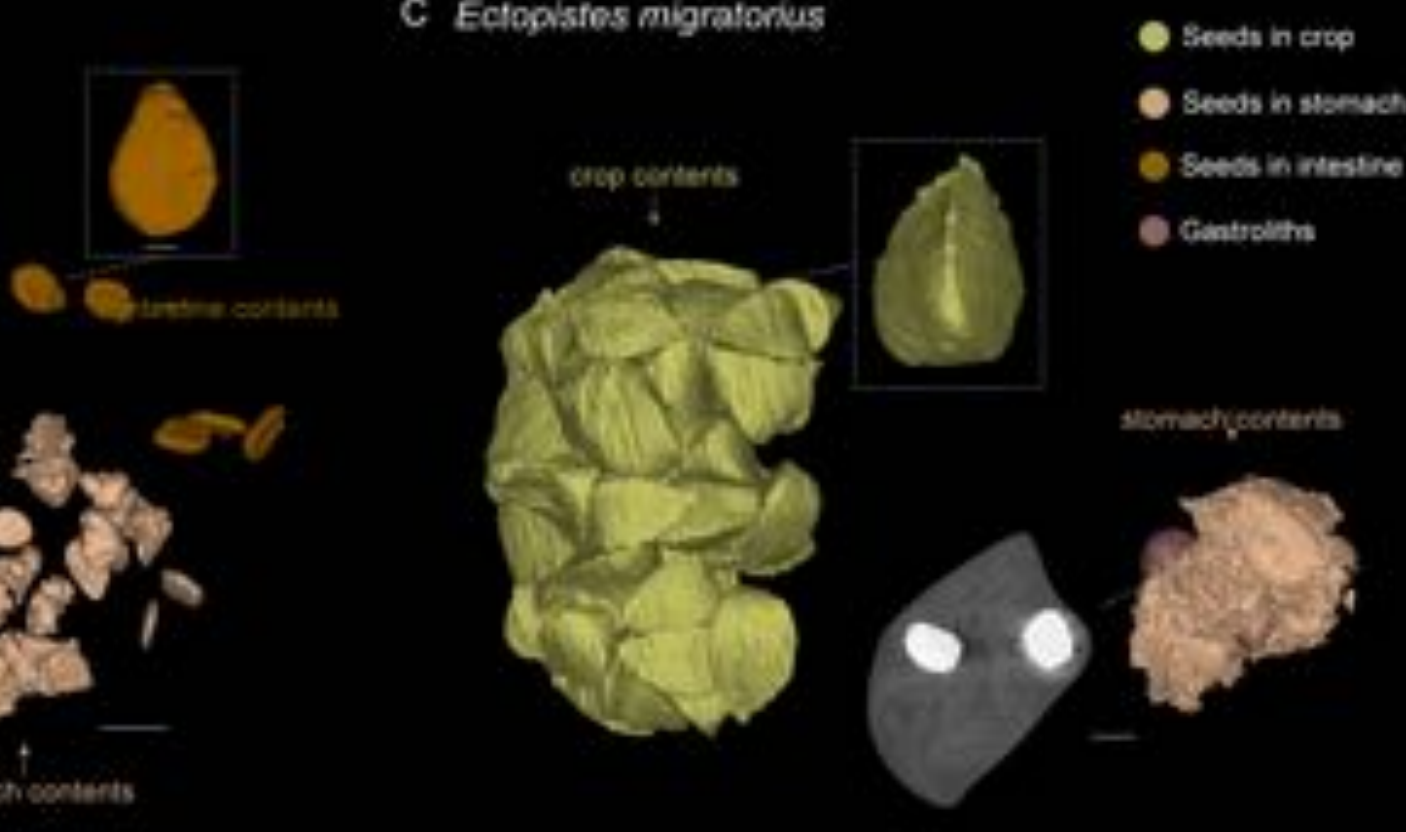

D Cocspiza fulfginosa

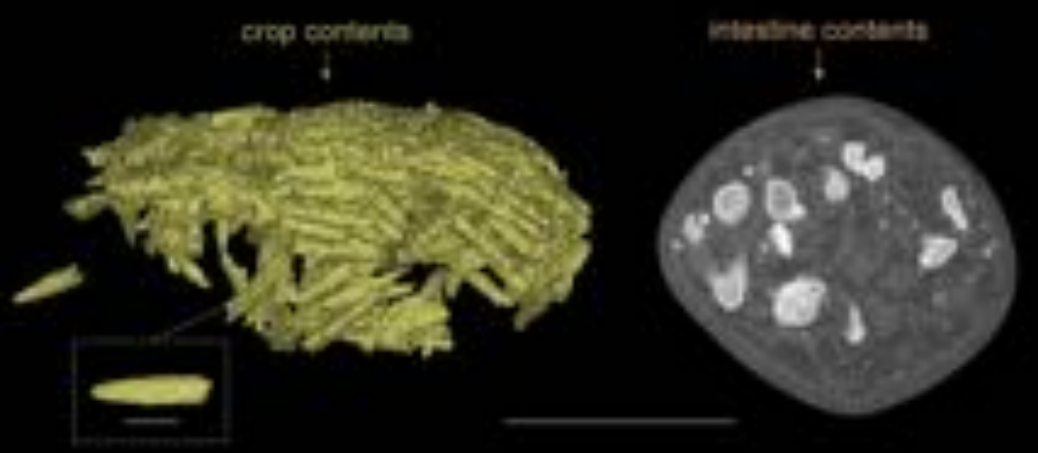

E Conuropsis earalinensis

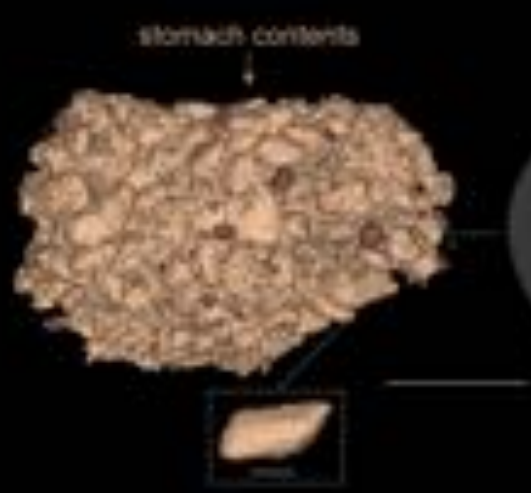


Menura novaeholliandlae
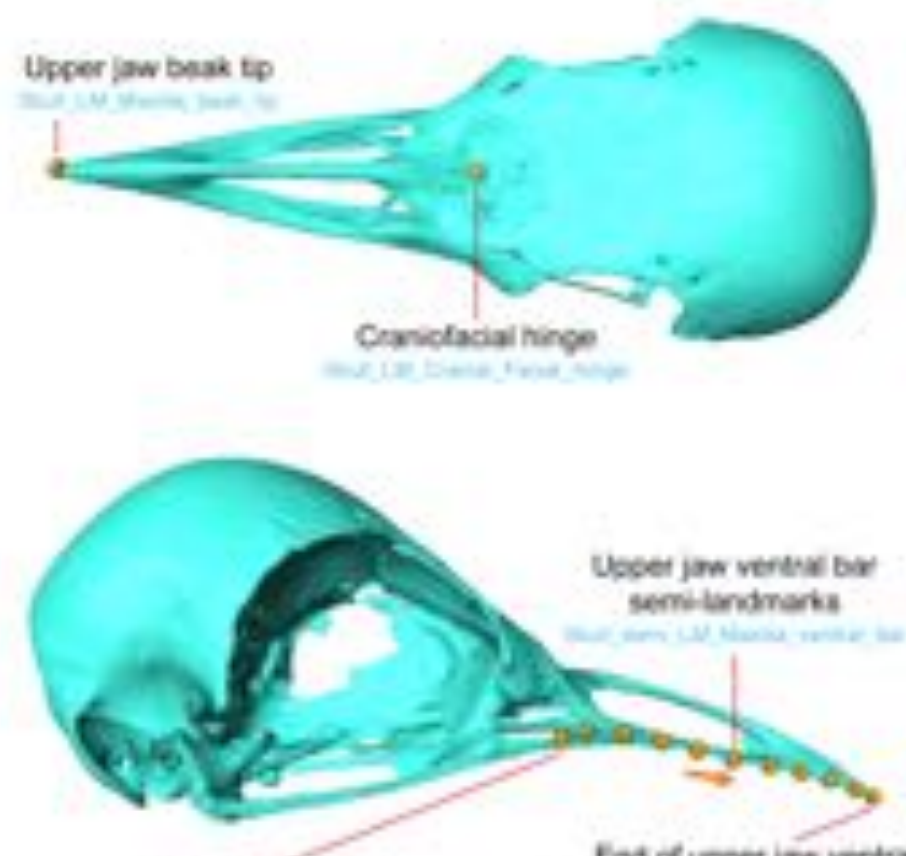

Blat of upser jan vererabar sentundmaks

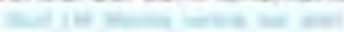

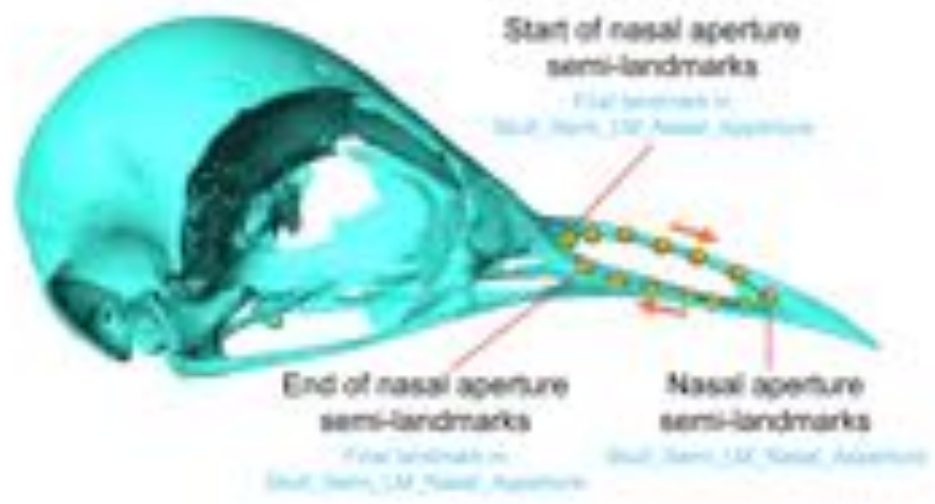

End of upper jam vertrat ba semilandnass Quccer jan beok fo?

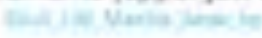

End of sov ter sernilinomiks Dugu bux end?

bant of jogl ber iem-landmirks

0ugar bay stort

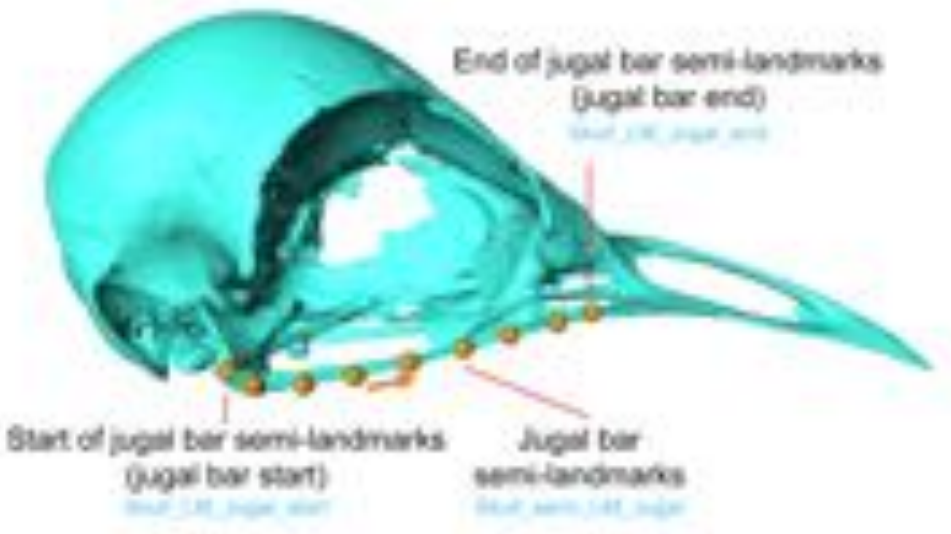

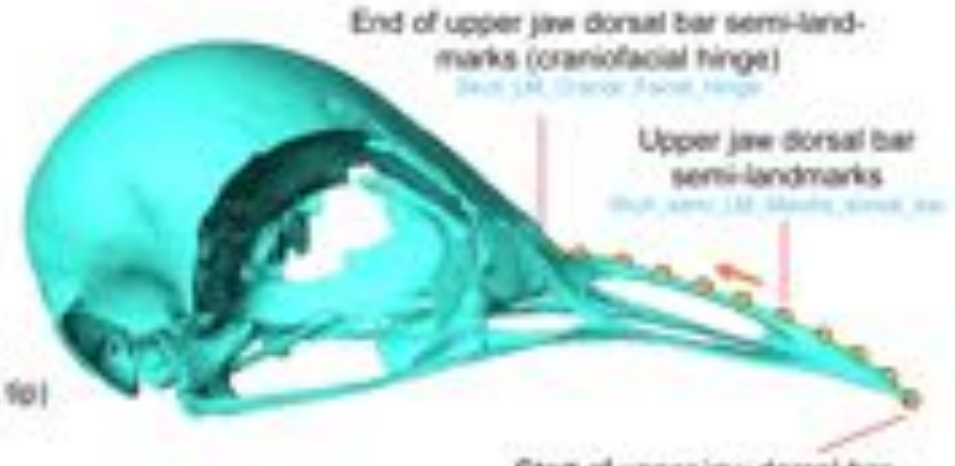

Stat of uover jew dowad ber semblandmarks fupper jaw beak tpo

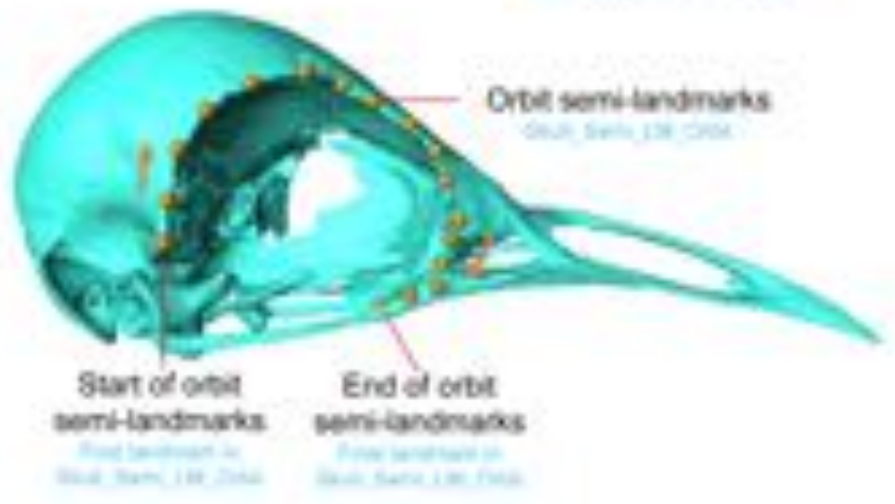

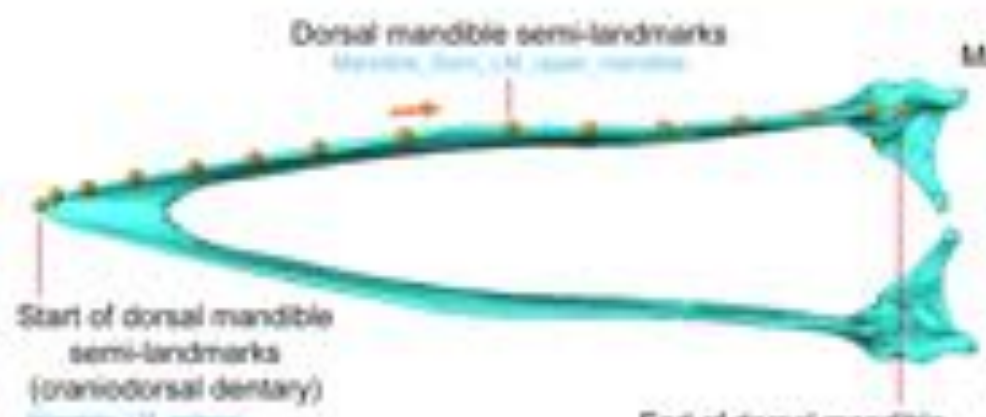

foravoousal destay)

incines
End of gorse mandibie sem-landnaka
Uandibula spmphanis sem-tandrasa

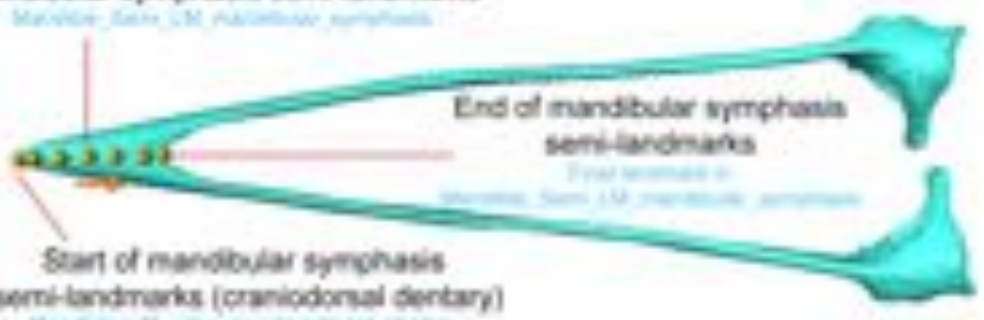

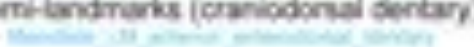

Ban of vertrs mondese sem-landmats fend of ronotidar smoheris soni indmaks!

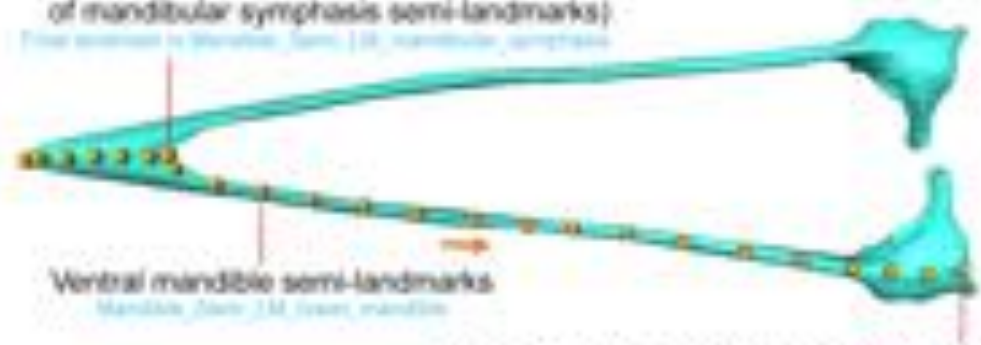

Fnd of verefal nansible sentlandmake:

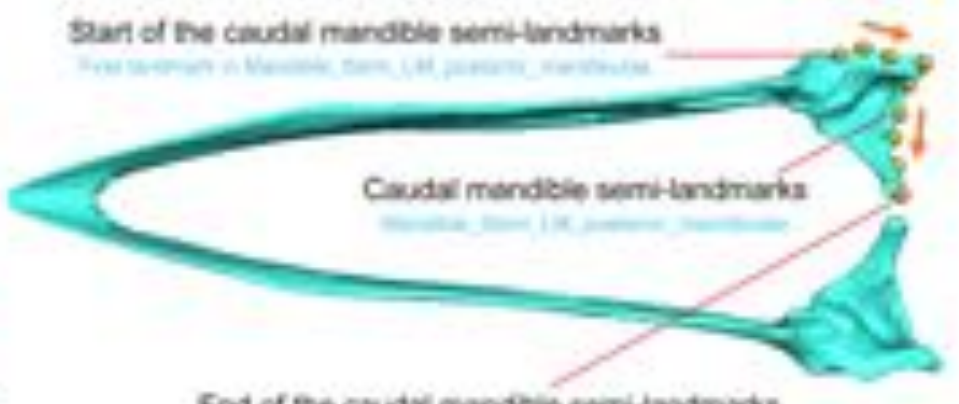

End of the caudx mandot sonitandmaks 

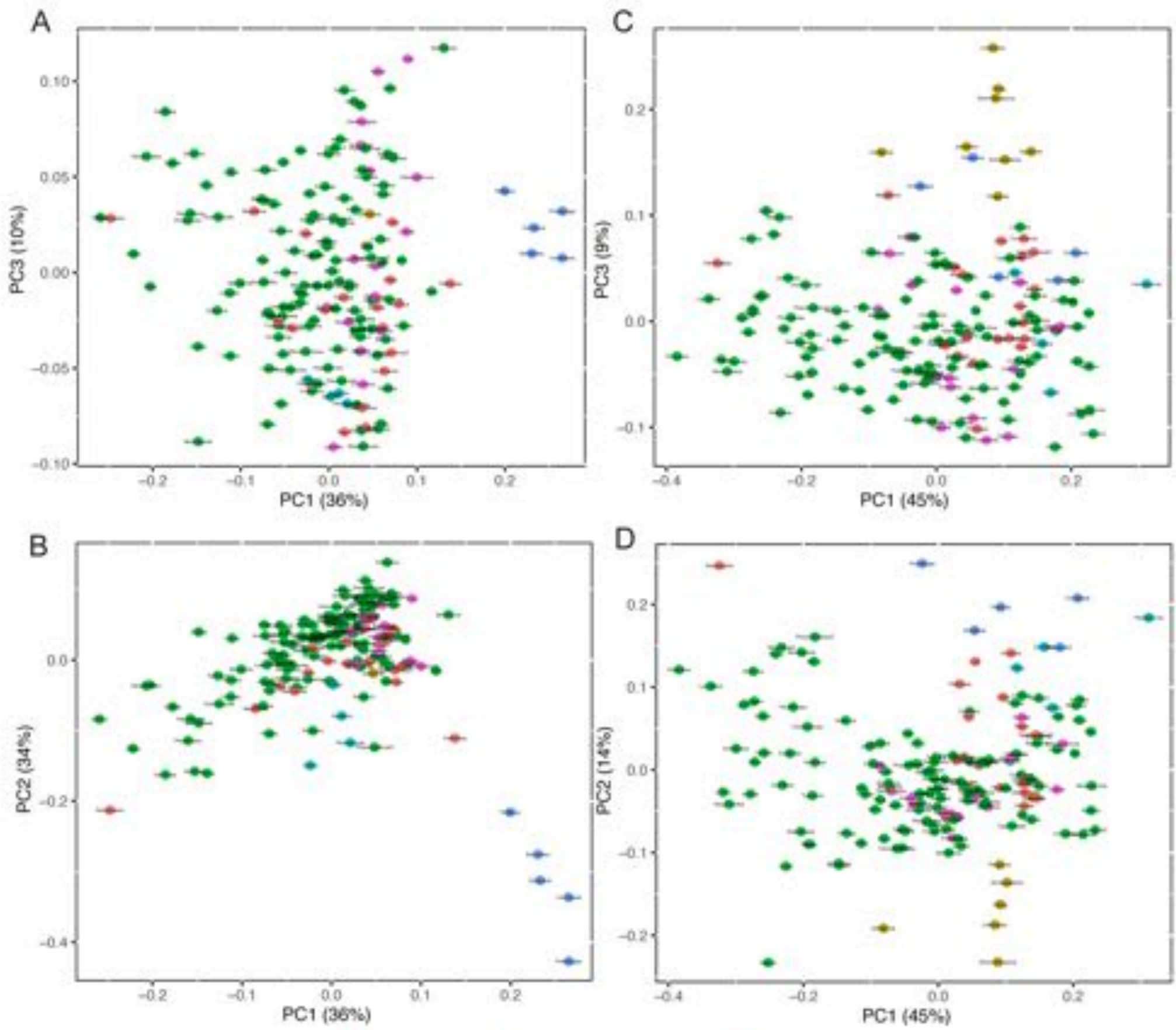
- Frua eaters
- Cover diess
- Seos-crackers (pantets)
- Mosoaric saxa
- Seed-achers baswarinesh - Seed-grinders 


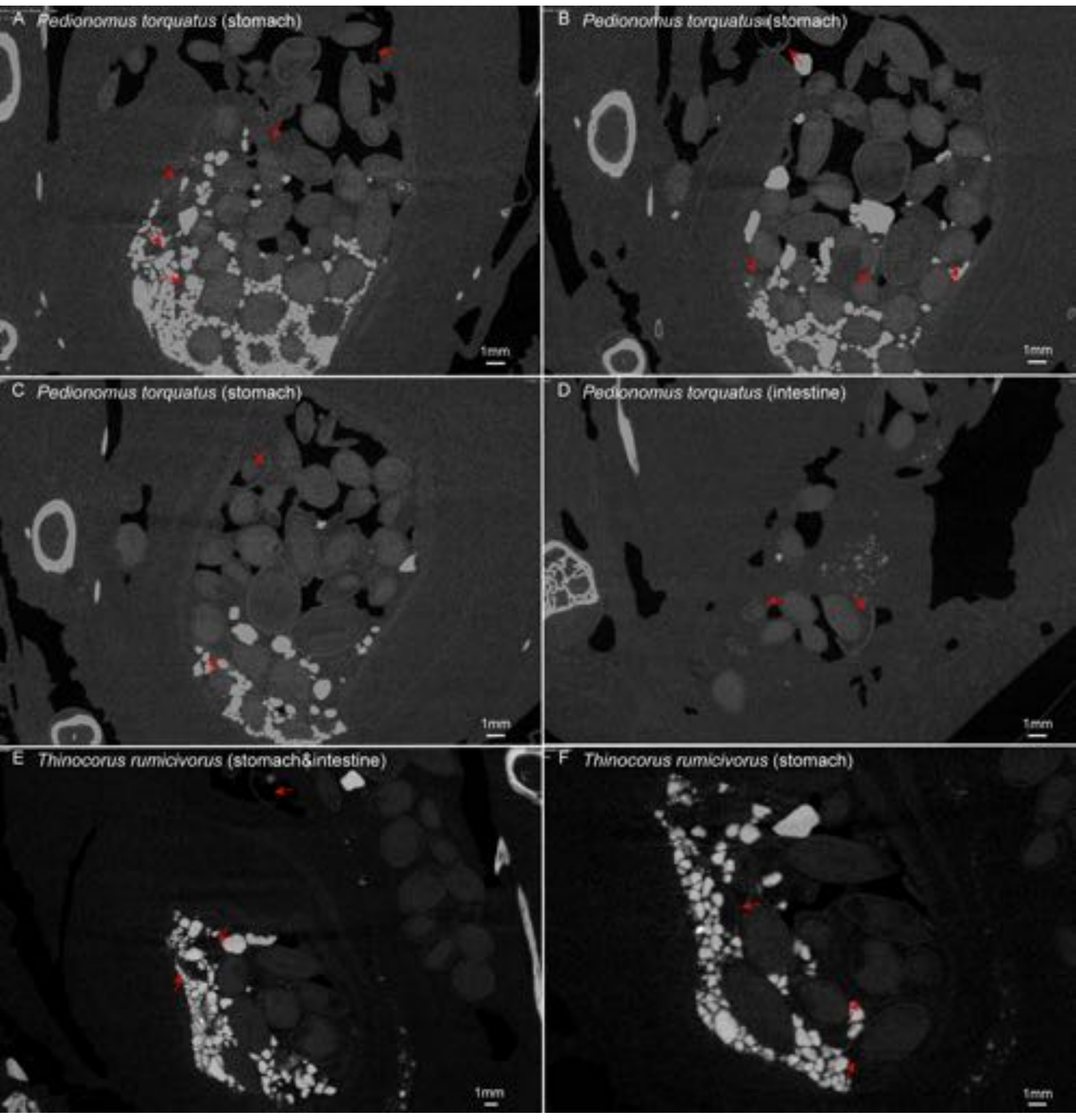

